\title{
Evaluation of two end-member-based models for regional land surface evapotranspiration estimation from MODIS data
}

\author{
Ronglin Tang ${ }^{\mathrm{a}}$, Zhao-Liang $\mathrm{Li}^{\mathrm{b}, \mathrm{c}, *}$ \\ a State Key Laboratory of Resources and Environment Information System, Institute of Geographic Sciences and Natural Resources Research, Beijing 100101, \\ China \\ ${ }^{\mathrm{b}}$ Key Laboratory of Agri-informatics, Ministry of Agriculture/Institute of Agricultural Resources and Regional Planning, Chinese Academy of Agricultural \\ Sciences, Beijing 100081, China \\ ' ICube, UdS, CNRS, 300 Boulevard Sebastien Brant, CS10413, 67412 Illkirch, France
}

\section{A R T I C L E I N F O}

\section{Article history:}

Received 12 May 2014

Received in revised form 25 October 2014

Accepted 15 December 2014

Available online 26 December 2014

\section{Keywords:}

Evapotranspiration

End-member

SEBAL

Surface temperature-vegetation index

triangle

Large aperture scintillometer (LAS)

\begin{abstract}
A B S T R A C T
The importance of accurate estimations of regional and global evapotranspiration (ET) has been recognized worldwide in the fields of hydrology, water resource management, meteorology, and global climate change. Given the different structures of the end-member-based surface energy balance algorithm for land (SEBAL) and surface temperature-vegetation index $\left(T_{s}-\mathrm{VI}\right)$ triangle models, which nonetheless use essentially the same definitions of dry and wet pixels, questions arise regarding the nature of the differences between the two models' estimated sensible heat fluxes and latent heat fluxes and what controls the heat flux differences. This study aims to investigate how the SEBAL model and the $T_{s}-\mathrm{VI}$ triangle method differ from each other in the regional evaporative fraction (EF) and ET estimates through analytical deduction and model applications. Because both the SEBAL model and the $T_{s}-\mathrm{VI}$ triangle model are of limited use when deep-layer soil moisture is moderately to significantly stressed, MODIS remote sensing data from 23 clear-sky overpass times between January 2010 and late October 2011, covering a wide range of soil moisture content and fractional vegetation cover conditions, are acquired to assess the two models over a non-water stressed study area on the North China plain. The results show that the SEBAL model is able to produce satisfactory sensible heat flux $(H)$ and latent heat flux (LE) estimates compared with ground-based large aperture scintillometer measurements at the Yucheng station, with small biases of $4.1 \mathrm{~W} / \mathrm{m}^{2}$ and $2.3 \mathrm{~W} / \mathrm{m}^{2}$ and root mean square errors (RMSEs) of $46.4 \mathrm{~W} / \mathrm{m}^{2}$ and $48.6 \mathrm{~W} / \mathrm{m}^{2}$, respectively. However, the $T_{s}-\mathrm{VI}$ triangle model produces much worse $H$ and LE estimates, with biases of $98.5 \mathrm{~W} / \mathrm{m}^{2}$ and $-92.2 \mathrm{~W} / \mathrm{m}^{2}$ and RMSEs of $119.3 \mathrm{~W} / \mathrm{m}^{2}$ and $115.5 \mathrm{~W} / \mathrm{m}^{2}$, respectively. Variations of pixel-by-pixel surface available energy and momentum roughness length over the study area are responsible for the differences of the $H$ and LE estimates between the two models. The SEBAL model produces larger EF and ET for most pixels than the $T_{s}-\mathrm{VI}$ triangle method when the same group of dry and wet pixels is applied, especially for pixels characterized by medium to high vegetation fractions or surface soil moisture contents. The $T_{S}-\mathrm{VI}$ triangle method is more sensitive to the surface temperatures of the dry and wet pixels than the SEBAL model. The findings from this study benefit the proper selection of end-member-based models for regional ET estimation and aid in quantifying the resultant uncertainties in the model-derived surface energy components.
\end{abstract}

(c) 2014 Elsevier B.V. All rights reserved.

\section{Introduction}

Evapotranspiration (ET, soil evaporation + canopy transpiration) controls the water and energy transfer between the land surface

\footnotetext{
* Corresponding author at: Key Laboratory of Agri-informatics, Ministry of Agriculture/Institute of Agricultural Resources and Regional Planning, Chinese Academy of Agricultural Sciences, Beijing 100081, China. Tel.: +86 1082105077.

E-mail address: lizhaoliang@caas.cn (Z.-L. Li).
}

and atmosphere at different temporal and spatial scales. The importance of accurate estimation of regional and global ET has been recognized worldwide in the fields of hydrology, water resource management, meteorology, and global climate change. Due to the large heterogeneities in the global land surface and the limited spatial representativeness and high cost of the intensive ground- and air-based instruments (e.g., weighing lysimeters, eddy covariance systems, Bowen ratio systems, and large aperture scintillometers) for ET measurement, a variety of models with varying degrees of complexities and accuracies have evolved from the empirical 
regression equation in the 1970s to the widely applied physicsbased one-source and two-source energy balance models in the 1990s and 2000s. These models are now being developed in combination with surface parameters retrieved through remote sensing over recent decades to estimate regional ET (Kalma et al., 2008; Li et al., 2009).

Of the various models, the end-member-based method, which relies on the surface hydrological contrast in the area of interest to determine the dry and wet pixels (end-members), is one of the most popular remote sensing methods for ET estimation. This method has been extensively evaluated and validated across a range of satellite sensors and field experiments at various spatial and temporal resolutions (Moran et al., 1994; Bastiaanssen, 1995; Jiang and Islam, 1999; Roerink et al., 2000; Merlin et al., 2014). In the endmember-based method, a dry pixel is generally characterized by a high surface temperature, a low fractional vegetation cover, a zero latent heat flux, and a zero surface soil moisture content, whereas a wet pixel in theory has a low surface temperature, a zero sensible heat flux, and a saturated surface soil moisture content. In the application of the end-member-based models, a basic premise is that an extreme surface hydrological contrast is exhibited in the area of interest at the given atmospheric conditions, and the corresponding representative dry and wet pixels can be directly or indirectly specified. When no more knowledge is available for the model calibration, some studies (Jiang and Islam, 2001; Bastiaanssen et al., 2005) have suggested calibrating the wet pixel from an open body of water or well-irrigated agricultural fields and to calibrate the dry pixel from a dry bare soil surface. In situations where the extreme hydrological contrast is not ensured within the study area, several authors (Moran et al., 1994; Zhang et al., 2005; Long et al., 2012) have tried to determine the dry and wet pixels from the surface energy balance theory with the aid of intensive near-surface meteorological and ground-based vegetation variables.

One representative model of the end-member-based method is the surface energy balance algorithm for land (SEBAL) developed by Bastiaanssen et al. (1998). By assuming a linear relationship between the pixel-by-pixel near-surface air temperature difference and the surface temperature within the area of interest, the SEBAL model does not mandatorily require measurements of near-surface air temperature as inputs, thus avoiding the interpolation/extrapolation of measurements collected from a limited number of stations. The advantage of the SEBAL model lies primarily in the minimum requirement of near-surface meteorological measurements, which makes it superior to other commonly applied one- and two-source energy balance models. Moreover, the a priori calibration that is often required in the application of the onesource bulk transfer equation for estimating sensible heat flux is also avoided by an automatic self-calibration process in the SEBAL model. Though the selection of the dry and wet pixels is often subject to the spatial-scale effect (Tang et al., 2013) and questions have been raised regarding the inconsistent definition of the near-surface temperature difference (recently defined as the air temperature difference between $2 \mathrm{~m}$ and $0.1 \mathrm{~m}$ ) (Norman et al., 2006), the SEBAL model has been examined and validated using direct and indirect field-scale and areal-averaged ET measurements from the Bowen ratio system, eddy covariance system, large aperture scintillometer, and water balance equation in more than 30 countries, with typical resulting accuracies of $85 \%, 95 \%$, and, on average, $96 \%$ at daily, seasonal, and annual scales, respectively (Bastiaanssen et al., 2005).

Another well-known end-member-based model, which is founded on the negative relationship between remotely sensed thermal emission and reflected spectral radiance, is the surface temperature $\left(T_{S}\right)$-vegetation index $(\mathrm{VI})$ space model. In this model, the changes in the slope of the $T_{S}$-VI scatterplot for a given atmospheric condition provide information on the spatial distribution of regional surface resistance (Nemani and Running, 1989), surface water content (Carlson et al., 1995), land use change (Lambin and Ehrlich, 1996), and air temperature (Prihodko and Goward, 1997). When both surface soil moisture content and fractional vegetation cover have a full range of variation, the two-dimensional scatterplot of $T_{s}-\mathrm{VI}$ forms a triangle bounded by the dry edge (the upper envelope of the maximum temperatures at each of the VI intervals, physically corresponding to the lower limit of the upper layer soil water content and ET) and the wet edge (the lower envelope of the minimum temperatures at each of the VI intervals, physically corresponding to sufficient soil water content and maximum ET). Jiang and Islam (1999) interpret the $\alpha$ factor of the Priestley-Taylor equation (Priestley and Taylor, 1972) in the $T_{S}-$ VI triangle framework and extend its applicability over the potentially evaporated surface to the stressed surface soil moisture content and partially vegetated area. The advantages are that this model requires the remote sensing $T_{S}$ and VI data alone as inputs and that this model is more simplified in terms of the model inputs and structure compared with the energy balance based physical models. Once the surface temperatures at dry and wet pixels are known, a two-step interpolation scheme in the $T_{s}-\mathrm{VI}$ triangle space is adopted to obtain the $\alpha$ factor for the intermediate pixels. It has been shown that as long as the dry and wet edges are determined properly, the triangle method proposed by Jiang and Islam (1999) appears to be able to provide accurate estimates of the evaporative fraction (EF) and ET at different spatial resolutions for a variety of surface covers and climate conditions (Jiang et al., 2004; Venturini et al., 2004; Stisen et al., 2008; Tang et al., 2010, 2011a).

Note that the wet edge in the $T_{S}-\mathrm{VI}$ triangle method is often simplified as a horizontal line, which indicates that the surface temperature at the potential rate condition does not vary across the different fractional vegetation covers and that the temperature at the wet edge in the triangle can be exchanged with that from the wet pixel in the SEBAL model. The dry edge in the $T_{S}-\mathrm{VI}$ triangle implicitly includes the dry pixel of the SEBAL model (corresponding to the intercept of the dry edge) and can be empirically determined by the two anchor points of the SEBAL model, if one assumes that the temperatures of the dry edge vary linearly with the fractional vegetation cover (or vegetation index). Given the different structures of the SEBAL and $T_{S}-\mathrm{VI}$ triangle models that essentially use the same definitions of the dry and wet pixels, questions arise regarding the nature of the differences between the two models' estimated sensible heat fluxes and latent heat fluxes when both models are applied to the same study area using the same group of dry and wet pixels and what controls the heat flux differences. To the best of our knowledge, there are no studies that have provided an exclusive or a comprehensive analysis of the differences between the SEBAL model and the $T_{S}$-VI triangle in estimating regional EF and ET. In the work of Long and Singh (2013), the $T_{s}-\mathrm{VI}$ triangle-derived EF was found to be lower than that from the SEBAL model when the impact of end-member selection on the model was evaluated. They discussed three key issues regarding the application of the end-member-based models, including how the variations of the end-members determine the EF and ET estimates, whether the end-members can be appropriately selected or determined, and whether the limiting edges of EF can represent the reality in the $T_{S}-$ VI triangle method. However, no in-depth discussion on the causes of the differences in the EF and ET estimates from the two models has ever been found.

The objective of this study is to investigate how the endmember-based SEBAL model and $T_{S}-$ VI triangle method differ from each other in the regional EF and ET estimation through analytical derivation and model applications. We examine the circumstances in which the EF and ET estimates of the SEBAL model are higher/lower than those of the triangle method. Section 2 provides a brief overview of the SEBAL model and the $T_{S}$-VI triangle 
method, the criterion on the selection of the dry and wet pixels within the study area, and the calculation of theoretical surface temperatures of the dry and wet pixels. From this section, we perform an analytical derivation to explicitly explain what determines the heat flux difference between the two models. Section 3 presents the study area, the ground-based large aperture scintillometer measurements, and the MODIS remote sensing data involved in the analysis. The results and discussion of the comparison between the SEBAL model and the $T_{S}-$ VI triangle method are given in Section 4. Summaries and conclusions are presented in Section 5.

\section{Methodology}

\subsection{Brief overview of the SEBAL and Triangle models}

\subsubsection{SEBAL model}

Detailed descriptions of the SEBAL model can be found elsewhere (Bastiaanssen et al., 1995, 1998, 2005; Tang et al., 2013). To better understand the nature of the end-member-based model, we present the SEBAL model here from a different perspective. According to the one-source bulk transfer formulation, the sensible heat flux $(H)$ of a given pixel can be simply related to the value at the "reference pixel", as follows:

$\frac{H}{H_{\text {ref }}}=\frac{d T_{s} / R_{a}}{d T_{s, \text { ref }} / R_{a, \text { ref }}}$

where $d T_{\mathrm{s}}$ and $R_{\mathrm{a}}$ are the near-surface air temperature difference and the aerodynamic resistance, respectively. The variables with a subscript "ref" are the values of the "reference pixel". If one assumes that the near-surface air temperature difference ranging from zero at the wet pixel (zero $H$ ) to the maximum at the dry pixel (zero ET) varies linearly with the surface temperature for similar atmospheric conditions (see Fig. 1a), Eq. (1) can be rewritten as follows:

$$
\frac{H}{H_{\text {ref }}}=\frac{T_{s}-T_{s, \text { wet }}}{T_{s, \text { ref }}-T_{s, \text { wet }}} \frac{R_{a, \text { ref }}}{R_{a}}
$$

where $T_{s, \text { wet }}$ is the surface temperature at the wet pixel. If the "reference pixel" is located over the dry bare soil surface (the dry pixel, with surface available energy equal to sensible heat flux), sensible heat flux at the given pixel can be expressed as:

$H=\frac{T_{s}-T_{s, \text { wet }}}{T_{s, \text { dry }}-T_{s, \text { wet }}} \frac{R_{a, d r y}}{R_{a}} H_{d r y}=\frac{T_{s}-T_{s, \text { wet }}}{T_{s, \text { dry }}-T_{s, \text { wet }}} \frac{R_{a, d r y}}{R_{a}}\left(R_{n}-G\right)_{d r y}$

and the EF for the given pixel by definition is then expressed as

$\mathrm{EF}=1-\frac{H}{R_{n}-G}=1-F \times \frac{T_{s}-T_{s, \text { wet }}}{T_{s, \text { dry }}-T_{s, \text { wet }}}$

with

$F=\frac{\left(R_{n}-G\right)_{d r y}}{\left(R_{n}-G\right)} \times \frac{R_{a, d r y}}{R_{a}}$

where $R_{n}-G$ is the surface available energy for the given pixel. The variables with the subscript "dry" are the values for the dry pixel. Note that by introducing the surface energy flux at the reference pixel and making an assumption of the linear relationship between near-surface air temperature difference and surface temperature, Eqs. (1)-(3) are originally developed to present straightforward how the sensible heat flux and evaporative fraction at a given pixel are linked to those at the reference pixel. In particular, when the reference pixel is located at the dry pixel, $H$ and $\mathrm{EF}$ at the given pixel are expressed directly as a function of surface temperatures at the end-members, which can also be deduced from the SEBAL model. Following the Bastiaanssen et al. (2005), the aerodynamic resistance in the aforementioned equations is estimated as:

$$
\begin{aligned}
R_{a}= & \frac{1}{k^{2} u_{200}}\left[\ln \left(\frac{z_{2}}{z_{1}}\right)-\psi_{h}\left(z_{2}\right)+\psi_{h}\left(z_{1}\right)\right] \\
& \times\left[\ln \left(\frac{200}{z_{o m}}\right)-\psi_{m}(200)\right]
\end{aligned}
$$

where $k$ is the von Karman's constant; $u_{200}$ is the wind speed at a blending height of $200 \mathrm{~m}$ above the ground and can be estimated from near-surface wind-speed measurements using a logarithmic wind profile; $z_{2}$ and $z_{1}$ are fixed at $2 \mathrm{~m}$ and $0.1 \mathrm{~m}$, respectively; $\Psi_{\mathrm{m}}$ and $\Psi_{\mathrm{h}}$ are the stability correction functions for momentum and heat transfer, respectively (Paulson, 1970); and $z_{o m}$ is the surface momentum roughness height ( 0.125 times the height of the vegetation), empirically determined in this study from the crop height and NDVI measurements at the Yucheng station (see Section 3). For the dry pixel, $z_{o m}$ is assigned a value of $0.005 \mathrm{~m}$ (Nishida et al., 2003).

Given that the surface available energy is equal to the sensible heat flux and the latent heat flux equals zero at the dry pixel and that the surface available energy is equal to the latent heat flux and the sensible heat flux equals zero at the wet pixel, the linear relationship (see Fig. 1a) between the near-surface air temperature difference $\left(d T_{S}\right)$ and the surface temperature $\left(T_{S}\right)$ can be estimated from the two anchor points with the following equations:

$d T_{s}=a T_{s}+b$

$a=\frac{\left(R_{n}-G\right)_{d r y} R_{a, d r y} /\left(\rho C_{p}\right)}{T_{s, d r y}-T_{s, \text { wet }}}$

$b=-a T_{s, \text { wet }}=-\frac{\left(R_{n}-G\right)_{d r y} R_{a, d r y} /\left(\rho C_{p}\right)}{T_{s, d r y}-T_{s, \text { wet }}} T_{s, \text { wet }}$

where $\rho$ is the air density and $C_{p}$ is the specific heat of air at constant pressure.

\subsubsection{Triangle model}

The most important advantage that makes the $T_{S}-\mathrm{VI}$ triangle method attractive in the scientific community is the simplicity of its model input and structure. The EF in the triangle method is expressed as follows (Jiang and Islam, 1999):

$\mathrm{EF}=\phi \frac{\Delta}{\Delta+\gamma}$

where $\phi$ is a combined-effect parameter (dimensionless) extended from the original $\alpha$ factor of the Priestley-Taylor equation; $\Delta$ is the slope of the saturated vapor pressure versus air temperature; and $\gamma$ is the Psychrometric constant.

To effectively derive the pixel-by-pixel ET and EF in the $T_{s}-\mathrm{VI}$ triangle, the two assumptions that have been generally made in previous studies involve (1) the linear variation of the $\phi$ parameter with the vegetation index between the global minimum ( 0$)$ and the maximum $((\Delta+\gamma) / \gamma)$ along the dry edge and $(2)$ the linear variation of $\phi$ with the surface temperature between the dry edge and the wet edge (see Fig. 1b). With this two-step linear interpolation scheme, the pixel-by-pixel $\phi$ is mathematically expressed:

$\phi=\phi_{\max } \frac{T_{s, d r y}-T_{s}}{T_{s, \text { dry }}-T_{s, \text { wet }}}$

where $\phi_{\max }$ is the global maximum in the triangle and equals $(\Delta+\gamma) / \gamma$ (often replaced with a constant of 1.26). Eqs. (8) and (9) clearly indicate that the EF is nearly equivalent to $\left(T_{s, \text { dry }}-T_{s}\right) /\left(T_{s, \text { dry }}-T_{s, \text { wet }}\right)$ for a given atmospheric condition with no consideration of the variations in the surface roughness and vegetation type. Note that the $T_{s}-\mathrm{VI}$ triangle method itself can only estimate pixel-by-pixel EF, to obtain regional ET, surface available energy needs to be further computed. Table 1 briefly summarizes 


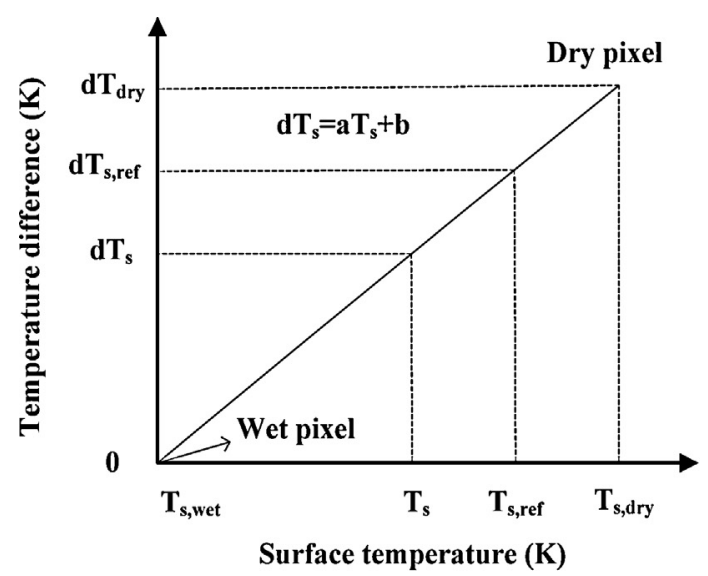

(a)

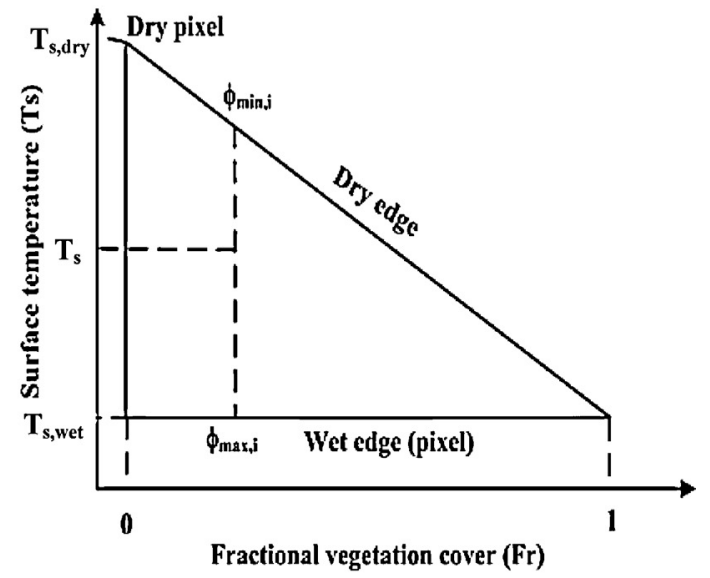

(b)

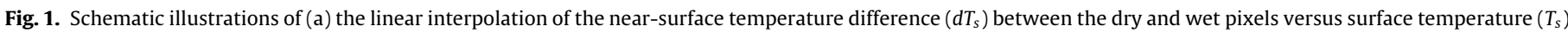

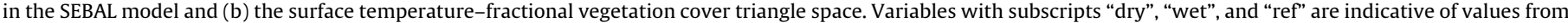
the dry, wet, and reference pixels, respectively. $\phi_{\min , \mathrm{i}}$ and $\phi_{\max , \mathrm{i}}$ are the minimum and maximum $\phi$ for a given vegetation index.

Table 1

Similarities and differences between the SEBAL and $T_{S}-$ VI triangle models (see the texts for the definitions of the variables).

\begin{tabular}{|c|c|c|}
\hline & SEBAL & $T_{S}-\mathrm{VI}$ triangle \\
\hline Model type & End-member-based & End-member-based \\
\hline Assumptions & Similar atmospheric forcings; dry and wet pixels can be identified & Similar atmospheric forcings; dry and wet pixels can be identified \\
\hline Dry pixel & Characterized by zero ET & Characterized by zero ET \\
\hline Wet pixel & Characterized by maximum ET (equals surface available energy) & Characterized by maximum ET (equals surface available energy) \\
\hline Inputs & $T_{s}$, NDVI (or vegetation height), $u, R_{n}, G$ & $T_{S}, \mathrm{NDVI}$ \\
\hline Outputs & ET and EF & $\mathrm{EF}$ \\
\hline EF equation & $\mathrm{EF}=1-\frac{\left(R_{n}-G\right)_{d r y}\left(R_{a}\right)_{d r y}}{\left(R_{n}-G\right) R_{a}} \frac{T_{s}-T_{s, w e t}}{T_{s, d r y}-T_{s, w e t}}$ & $\mathrm{EF}=\phi_{\max } \frac{\Delta}{\Delta+\gamma} \frac{T_{s, d r y}-T_{s}}{T_{s, d r y}-T_{s, w e t}}$ \\
\hline
\end{tabular}

the similarities and differences between the SEBAL and $T_{S}-\mathrm{VI}$ triangle models.

\subsubsection{Estimation of surface net radiation and soil heat flux}

The surface net radiation $\left(R_{n}\right)$ is computed from the downward and upward shortwave and longwave radiations at the ground:

$R_{n}=(1-r) R_{g}+\varepsilon_{s} L_{d}-L_{u}$

where $r$ is the surface albedo; $R_{g}$ is the global solar radiation, estimated as a function of the atmospheric transmissivity, solar zenith angle, solar constant, and eccentricity of the Earth; $\varepsilon_{s}$ is the surface emissivity, estimated by the expression proposed by Liang (2004) from the MODIS emissivities at the 31 and 32 bands; and $L_{d}$ and $L_{u}$ are the downward atmospheric radiation and upward surface-emitted longwave radiation, respectively, estimated using the Stefan-Boltzmann law. The surface albedo in this study is derived using the empirical equation previously regressed with the MODIS surface reflectance products (MOD09GA or MYD09GA) at the Yucheng station (Tang et al., 2013):

$r=0.25125 r_{1}+0.17588 r_{2}+0.10050 r_{3}+0.10050 r_{4}$

$$
+0.12060 r_{6}+0.25125 r_{7}
$$

where $r_{i}$ is the surface reflectance in band $i(i=1,2,3,4,6,7)$.

Soil heat flux $(G)$ is often expressed as a fraction of the surface net radiation from the remote sensing perspective (Bastiaanssen et al., 1998; Su, 2002). In this study, a local calibration made by Tang et al. (2013) to the originally proposed equation by Bastiaanssen et al. (1998) is applied to adapt to the MODIS normalized difference vegetation index (NDVI) and surface temperature $\left(T_{S}\right)$ products for the pixel-by-pixel estimation of $\mathrm{G}$ :

$G / R_{n}=\left(0.576-0.382 \mathrm{NDVI}-0.007\left(T_{s}-273.15\right)\right)$

\subsection{Selection of observed end-member pixels for the models}

The proper selection of the dry and wet pixels that are indicative of the zero ET and maximum ET over the study area directly determines the success of the implementation of the SEBAL and $T_{S}-$ VI triangle models. Because there has been no consensus on this issue, the dry and wet pixels in this study are selected based on a land-use map (see Fig. 2a), following the operational and automatic rules that have been adapted by Tang et al. (2013) from previous studies as follows.

(i) The selection of the dry pixel. Select the pixel that is characterized by the highest temperature and the arable land use in the study area as the dry pixel.

(ii) The selection of the wet pixel. Preferentially select the pixel that is characterized by the lowest temperature over a body of water (NDVI <0, albedo <0.05) at an elevation below $100 \mathrm{~m}$ above sea level (mountainous areas are excluded) as the wet pixel. If no water body can be identified from the satellite data, the pixel with the lowest surface temperature and NDVI $>0$ at an elevation less than $100 \mathrm{~m}$ above sea level should be selected as the wet pixel.

\subsection{Calculation of true end-member pixels in theory}

To reduce the uncertainty in the manual selection of dry and wet pixels and to minimize the effects of this uncertainty, the end-member pixels are also calculated in this study under given atmospheric conditions using the surface energy balance theory. Because the end-member pixels have been theoretically deduced by several authors in previous studies for the retrieval of ET and soil moisture content (Moran et al., 1994; Nishida et al., 2003; Zhang 


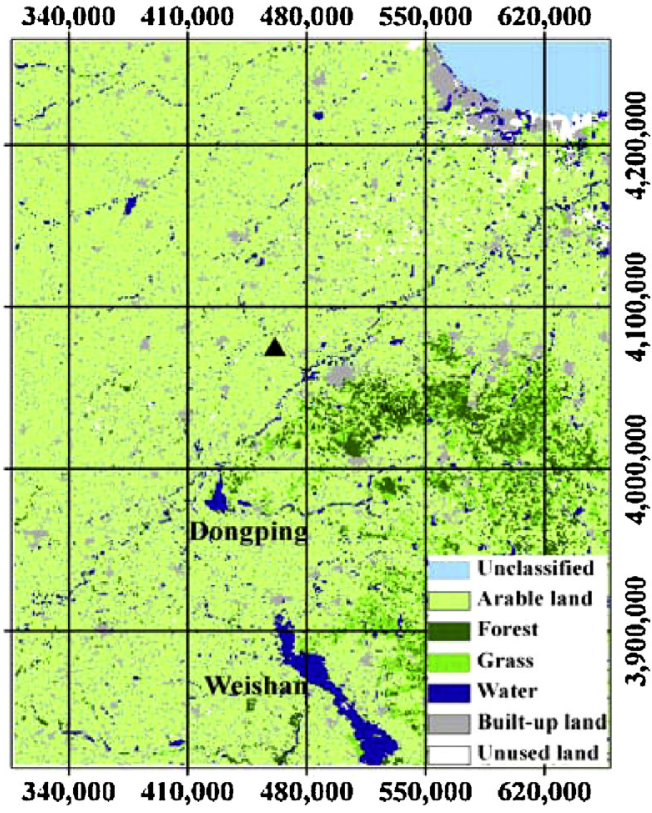

(a)

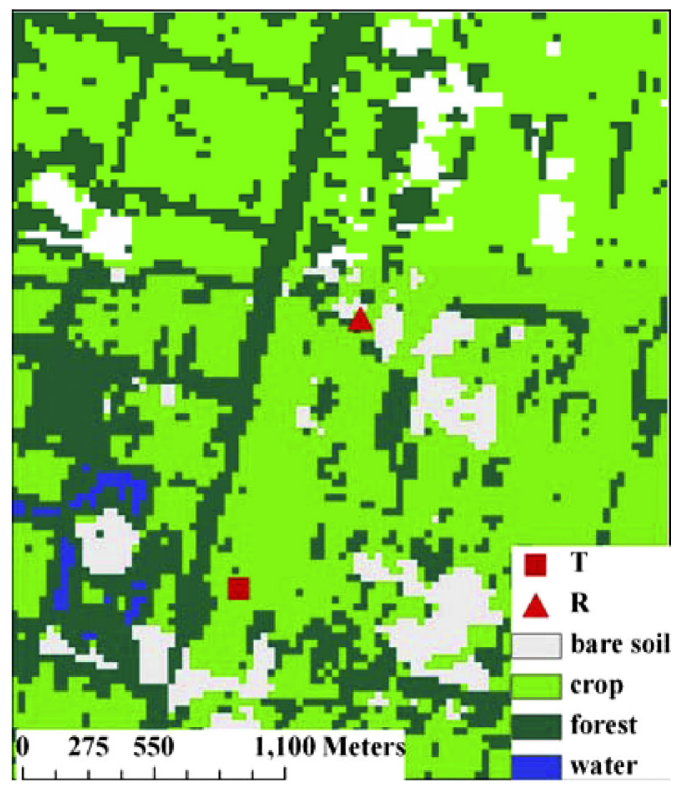

(b)

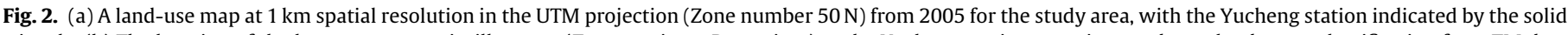

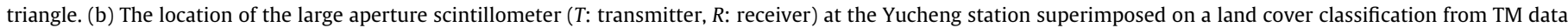
acquired on August 30, 2009.

et al., 2005; Long et al., 2012), we will only present the most relevant equations that are associated with the regional EF and ET estimates from the SEBAL and $T_{S}-\mathrm{VI}$ triangle models. Given that the surface available energy equals the sensible heat flux and the latent heat flux equals zero, the surface temperature of the dry pixel at the satellite overpass time under a given atmospheric condition can be derived by solving the surface energy balance equation as follows:

$T_{s, d r y}=\frac{R_{n, 0}(1-\Gamma)}{\rho C_{p} / R_{a, d r y}+4 \varepsilon_{s} \sigma T_{a}^{3}(1-\Gamma)}+T_{a}$

$R_{n, 0}=(1-r) R_{g}+\varepsilon_{s} \varepsilon_{a} \sigma T_{a}^{4}-\varepsilon_{s} \sigma T_{a}^{4}$

where $\Gamma$ is the ratio of $\mathrm{G}$ to $R_{n}$ for the dry pixel, fixed at 0.296 in this study by analyzing the long-term ground-based measurements at the Yucheng station; $R_{a, d r y}$ is the aerodynamic resistance for the dry pixel (momentum roughness length is 0.005$) ; \varepsilon_{s}$ is the surface emissivity; $\varepsilon_{a}$ is the atmospheric emissivity; $\sigma$ is the Stefan-Boltzmann constant; $T_{a}$ is the air temperature; and $\mathrm{r}$ is the surface albedo, calculated as the maximum of the ratio of half-hourly reflected solar radiation to downward solar radiation at the Yucheng station. In the process of calculating $T_{s, d r y}$, the air temperature difference for the dry pixel can also be obtained without extra effort.

The determination of the theoretical surface temperature for the wet pixel is more difficult and problematic than that of the dry pixel. Some studies (Long et al., 2012; Jiang and Islam, 2001; Carlson, 2007) have suggested using the areal-average air temperature measured near the ground or the satellite-derived water body surface temperature as the theoretical surface temperature. The former is believed to be a very good candidate for the theoretical surface temperature when the underlying surface is close to a potentially evaporating condition. However, if the underlying surface is significantly water-stressed, use of the areal-average air temperature will overestimate the theoretical surface temperature of the wet pixel. The restricting factor for the use of the satellitederived water-body surface temperature is the presence of thin cirrus clouds that cannot be detected but will cause an underestimation of the theoretical surface temperature. Different from the previous studies, considering that the $T_{s}-\mathrm{VI}$ triangle model is sensitive to the surface temperatures at the dry and wet pixels, the theoretical surface temperature at the wet pixel in this study is calculated by inverting Eqs. (8) and (9) using the ground-based EF measurements and the theoretical surface temperature of the dry pixel. The observed and true end-members that are selected in Section 2.2 and calculated in this section, respectively, will be applied to the SEBAL and $T_{S}-$ VI triangle models for $H$ and ET comparisons and validations.

\section{Study area and data}

\subsection{Study area}

The study area (Fig. 2a) covers an area of approximately $155,650 \mathrm{~km}^{2}$ in the North China Plain, between the coordinates $34.5^{\circ} \mathrm{N}$ to $38.5^{\circ} \mathrm{N}$ and $114.8^{\circ} \mathrm{E}$ to $118.8^{\circ} \mathrm{E}$. The area is characterized by a humid to sub-humid climate in the warm temperate zone and a brunisolic soil type. The surface elevation over the study area in most cases varies from 0 to $400 \mathrm{~m}$ above sea level (a mountain, with a surface elevation of $>100 \mathrm{~m}$ and primarily covered by forest, is located in the southeast portion of the study area). The land use and land cover types are composed of arable (wheat, corn, cotton, sorghum, and peanut agriculture), forest, grassland, water bodies (lakes and rivers), and built-up land (Fig. 2a). Two large lakes (Weishan Lake and Dongping Lake) are located in the south and south-central portions of the study area. The Yucheng Comprehensive Experimental Station (indicated by the solid black triangle in Fig. 2a, hereafter referred to as the Yucheng station) is located in the center of the study area, where winter wheat (growing season: late October to next early June) and summer corn (growing season: mid-June to early October) are rotated and from which ground-based measurements of meteorological variables and surface energy components are used to drive or validate the models. The annual temperature and precipitation at the Yucheng station are approximately $13.1^{\circ} \mathrm{C}$ and $528 \mathrm{~mm}$, respectively. 
Readers should refer to Tang et al. (2011b) for more detailed information about the Yucheng station.

The measurement height of the involved meteorological variables (composed of air temperature, wind speed, relative humidity, and atmospheric pressure) are adjusted at the Yucheng station twice a year, usually in late July or early August $(\sim 4.2 \mathrm{~m})$ and late October or early November $(\sim 2.9 \mathrm{~m})$, corresponding to the early corn and wheat growing seasons, respectively. The downward and upward shortwave and longwave radiations at the Yucheng station are measured by CNR-1 (Kipp \& Zonen) radiometers and soil heat flux by a single HFP01 soil heat flux plate (HukseFlux) at a soil depth of $2 \mathrm{~cm}$. The heat storage above the heat flux plate is not accounted for. Quadratic equations are regressed for the wheat and corn heights that were measured at the Yucheng station three to four times for the different growth seasons. Table 2 provides a list of model inputs at the Yucheng station for the SEBAL and $T_{s}-\mathrm{VI}$ triangle models over the selected clear-sky satellite overpass times from January 2010 to late October 2011. It can be seen that a wide range of variations are covered in the surface vegetation cover and height and in the meteorological variables of air temperature (for the downward longwave radiation estimation), wind speed, relative humidity, and global solar radiation.

\subsection{Large aperture scintillometer measurements}

A large aperture scintillometer (LAS, Kipp \& Zonen Inc.) oriented northeast-southwest regularly measures turbulent sensible heat flux at the Yucheng station (Fig. 2b, note that a malfunction occurred between mid-September to late December 2010). The heights of the receiver $\left(36.8314^{\circ} \mathrm{N} / 116.5717^{\circ} \mathrm{E}\right)$ and the transmit$\operatorname{ter}\left(36.8212^{\circ} \mathrm{N} / 116.5661^{\circ} \mathrm{E}\right)$ of the LAS are fixed at approximately $8.8 \mathrm{~m}$ above the ground, and the path length between the two sensors is $1240 \mathrm{~m}$. A built-in data logger is used to record the logarithm of the structure parameter of the refractive index of air with a base of $10\left(\mathrm{UCn}^{2}\right)$, the signal strength, and the variance of $\mathrm{UCn}^{2}$ every $10 \mathrm{~min}$. The Monin-Obukhov similarity theory is introduced to derive iteratively sensible heat flux from the LAS raw measurement and support meteorological and vegetation height data. The details on the post-processing of the raw LAS signal at the Yucheng station were given in our prior paper (Tang et al., 2011b). The Bowen ratio involved in this post-processing is estimated together with the LAS-derived sensible heat flux from the measured net radiation and soil heat flux using the energy balance equation. Our prior study (Tang et al., 2011b) on the post-processing of the raw LAS measurements conducted between early May to late September 2009 at the Yucheng station showed that the overall uncertainty of the LAS-derived sensible heat flux caused by the LAS raw data and support data is approximately $12 \%$. The prior study also demonstrated that the LAS could provide more representative values of the heat fluxes than the eddy covariance system at the MODIS pixel scale to compare with model output.

Half-hourly measurements of surface net radiation, soil heat flux, and LAS-derived sensible heat flux from the year 2010 to late October 2011, covering different soil moisture conditions and crop growth stages at the Yucheng station, are used to compare and validate the SEBAL and $T_{S}-$ VI triangle models.

\subsection{MODIS data}

The remote sensing data from the MODIS sensors onboard the Terra and Aqua satellites, which cover the entire earth's surface every 1-2 days and can be retrieved from the Land Processes Distributed Active Archive Center (LP DAAC), are used in this study for the estimation of regional EF and ET. The MODIS remote sensing data are composed of a land surface temperature/emissivity product (MOD11_L2, MYD11_L2) with a $1000 \mathrm{~m}$ spatial resolution and a surface reflectance product (MOD09GA, MYD09GA) with a $500 \mathrm{~m}$ spatial resolution. The land surface temperature/emissivity product provides the model with the surface temperature, surface emissivity, solar zenith angle, and sensor overpass time. The surface reflectance product is applied to estimate the NDVI and the broadband surface albedo.

To reduce the effect of the large sensor view angle on the surface temperature (Li et al., 2001, 2004, 2013a, 2013b) and to satisfy the requirement of an extreme surface hydrological contrast within the study area, the following rules have been adopted to rigorously select the MODIS/Terra and MODIS/Aqua products. First, the maximum sensor-view zenith angle must be smaller than $45^{\circ}$ within the entire study area. Second, at least $80 \%$ of the study area (pixels) must be covered by pixels with valid surface temperatures. With these rules and restricted by ground-based measurements for the validation, the number of the selected clear-sky MODIS/Terra and MODIS/Aqua overpasses is significantly reduced to a total of 23 (16 Terra overpasses and 7 Aqua overpasses) between January 2010 and late October 2011. Model inputs of the surface albedo, emissivity, temperature, and NDVI retrieved from the MODIS remote sensing data are illustrated in Table 2 for the selected 23 clear-sky overpasses.

\section{Results and discussion}

\subsection{Comparison of the selected and calculated surface temperatures at the end-member pixels}

Before we compare the model-derived surface energy components with the ground-based measurements, using the rules and the calculation method (as shown in Sections 2.2 and 2.3, respectively) and the ground-based LAS-measured EF measurements at the Yucheng station, Fig. 3 presents a comparison of the theoretical and selected surface temperatures of the dry and wet pixels at the satellite overpass times for the 23 clear-sky days of the study area. At the different satellite overpass times (characterized by varying atmospheric conditions, crop types and growth stages, and surface soil moisture contents), both the theoretical and selected surface temperatures of the dry and wet pixels have been shown to vary greatly between the 23 clear-sky days. Specifically, the surface temperatures of the dry and wet pixels varied from $\sim 280 \mathrm{~K}$ and $\sim 267 \mathrm{~K}$, respectively, on a winter day (day of year 23 in 2011) to over $320 \mathrm{~K}$ in summer and $\sim 300 \mathrm{~K}$ in autumn. On day of year (DOY) 23 in 2011, the LAS-measured $H$ was higher than the surface available energy, which created a negative EF value and a physically unreasonable theoretical surface temperature that was higher for the wet pixel than for the dry pixel. The theoretical surface temperature at the wet pixel has been assumed to equal the surface temperature of the selected wet pixel for further analysis. Clearly, a seasonal variation of the surface temperatures at the dry and wet pixels can be observed.

It is found that the theoretical surface temperature at the dry pixel can be higher, close to, and lower than the surface temperature at the selected dry pixel. Neglecting the error/uncertainty from the calculation method itself, the higher theoretical surface temperatures than the selected value of the dry pixel on some clear-sky days are associated with the inappropriate selection or non-existence of the dry pixel, which means that the selected dry pixel is not the true dry pixel assumed to have a zero surface soil moisture content and ET in the study area. Under this condition, the regional EF and ET from both the SEBAL model and the $T_{S}-$ VI triangle method will be theoretically underestimated. The theoretical surface temperature that was lower than the selected 
Table 2

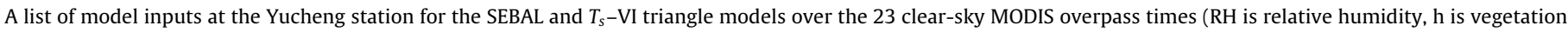
height, $\mathrm{u}$ is wind speed. See the text for the definitions of other variables).

\begin{tabular}{|c|c|c|c|c|c|c|c|c|c|c|c|}
\hline Year & Day & $T_{a}\left({ }^{\circ} \mathrm{C}\right)$ & $u(\mathrm{~m} / \mathrm{s})$ & $\mathrm{RH}(\%)$ & $R_{g}\left(\mathrm{~W} / \mathrm{m}^{2}\right)$ & $r$ & $\varepsilon_{s}$ & $T_{S}\left({ }^{\circ} \mathrm{C}\right)$ & NDVI & $h(\mathrm{~m})$ & Sensor \\
\hline \multirow{6}{*}{2010} & 130 & 22.08 & 4.5 & 30 & 950 & 0.136 & 0.972 & 25.31 & 0.654 & 0.79 & \multirow{16}{*}{ Terra } \\
\hline & 139 & 26.23 & 2.8 & 42 & 941 & 0.124 & 0.972 & 28.51 & 0.672 & 0.79 & \\
\hline & 166 & 34.49 & 4.4 & 31 & 858 & 0.169 & 0.972 & 37.83 & 0.359 & 0.20 & \\
\hline & 178 & 32.51 & 4.2 & 44 & 654 & 0.168 & 0.972 & 35.69 & 0.311 & 1.08 & \\
\hline & 210 & 32.35 & 3.6 & 69 & 672 & 0.191 & 0.972 & 30.91 & 0.567 & 2.43 & \\
\hline & 228 & 29.55 & 1.8 & 60 & 754 & 0.109 & 0.972 & 30.27 & 0.77 & 2.41 & \\
\hline \multirow{10}{*}{2011} & 23 & -3.58 & 2.1 & 22 & 544 & 0.162 & 0.973 & 5.69 & 0.304 & 0.08 & \\
\hline & 30 & 0.378 & 2.1 & 19 & 547 & 0.162 & 0.972 & 8.23 & 0.285 & 0.08 & \\
\hline & 69 & 10.88 & 3.4 & 30 & 719 & 0.149 & 0.973 & 19.17 & 0.263 & 0.08 & \\
\hline & 85 & 14.11 & 5.1 & 22 & 762 & 0.141 & 0.973 & 17.37 & 0.347 & 0.09 & \\
\hline & 94 & 14.42 & 1.4 & 26 & 820 & 0.148 & 0.973 & 22.21 & 0.461 & 0.17 & \\
\hline & 101 & 15.22 & 3.6 & 37 & 839 & 0.137 & 0.973 & 20.69 & 0.555 & 0.25 & \\
\hline & 114 & 15.99 & 2.7 & 39 & 882 & 0.158 & 0.973 & 22.91 & 0.671 & 0.42 & \\
\hline & 133 & 23.57 & 3.2 & 27 & 956 & 0.116 & 0.972 & 26.27 & 0.71 & 0.75 & \\
\hline & 265 & 24.01 & 1.4 & 43 & 786 & 0.116 & 0.973 & 25.95 & 0.681 & 2.85 & \\
\hline & 288 & 18.15 & 4.9 & 34 & 686 & 0.164 & 0.972 & 24.31 & 0.324 & 0.05 & \\
\hline \multirow{3}{*}{2010} & 121 & 24.86 & 4.9 & 45 & 869 & 0.138 & 0.972 & 27.53 & 0.627 & 0.79 & \multirow{7}{*}{ Aqua } \\
\hline & 254 & 29.65 & 1.3 & 45 & 723 & 0.118 & 0.972 & 29.93 & 0.737 & 2.41 & \\
\hline & 136 & 25.42 & 1.7 & 41 & 790 & 0.149 & 0.972 & 30.49 & 0.677 & 0.79 & \\
\hline \multirow{4}{*}{2011} & 143 & 21.49 & 3.7 & 52 & 908 & 0.154 & 0.972 & 27.19 & 0.67 & 0.79 & \\
\hline & 264 & 24.9 & 1.6 & 29 & 719 & 0.117 & 0.973 & 27.47 & 0.746 & 2.85 & \\
\hline & 268 & 27.05 & 2.6 & 33 & 608 & 0.106 & 0.973 & 27.25 & 0.702 & 2.85 & \\
\hline & 289 & 23.86 & 1.4 & 25 & 566 & 0.158 & 0.973 & 30.69 & 0.331 & 0.05 & \\
\hline
\end{tabular}

value of the dry pixel for a given satellite overpass time may be explained by the use of the artificially determined variables in Eq. (13) and attributed to different atmospheric conditions that have been assumed to be similar in selecting the dry pixel. For example, when we apply Eq. (13) to calculate the theoretical surface temperature at the dry pixel, both the surface albedo (the ratio of reflected to downward solar radiation) and the ratio of $G$ to $R_{n}$ are obtained by using the corresponding maxima of the groundbased measurements at the Yucheng station. This may introduce some uncertainties, especially when the soil type and soil texture at the Yucheng station are different from those at the selected dry pixel. Moreover, there will also be measurable differences in the atmospheric conditions between the selected dry pixel and the Yucheng station under some cases, given the large size of the study area in this study. The theoretical surface temperature of the wet pixel calculated by inverting the EF formulation in the $T_{S}-\mathrm{VI}$ triangle method in most cases is found to be higher than the surface temperature of the selected wet pixel, which may be explained either by the effect of the cirrus clouds on the surface temperature of the selected wet pixel or by the uncertainty in the LAS-measured EF measurements. Note that given the solid physical basis of Eq. (13), which is deduced from the surface energy balance theory, one may have more confidence in the calculation of the theoretical surface temperature of the dry pixel. However, the calculation of the theoretical surface temperature of the wet pixel in this study using a calibration method seems to be highly uncertain due to the oversimplified structure of the $T_{s}-\mathrm{VI}$ triangle method, which may incur errors in the regional EF estimation. In the following sections, we will further evaluate the impact of the calibrated theoretical surface temperature of the wet pixel on the SEBAL-estimated EF and ET. Using air temperature measurements or water body surface temperatures as the theoretical surface temperature for the wet pixel will also be briefly discussed.

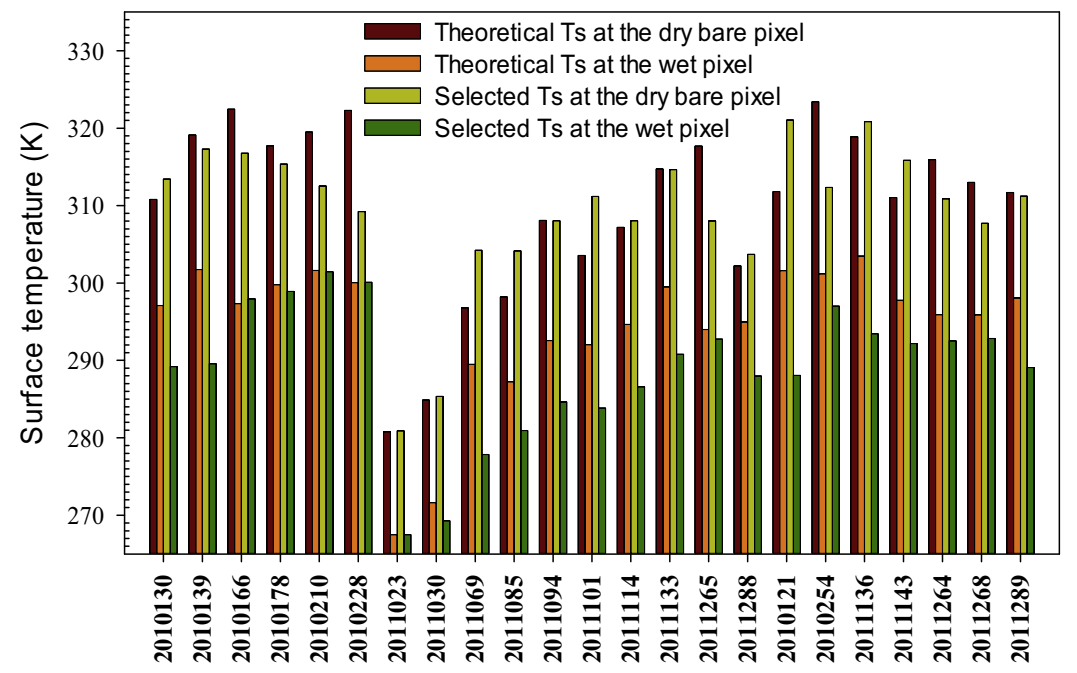

Day of Year

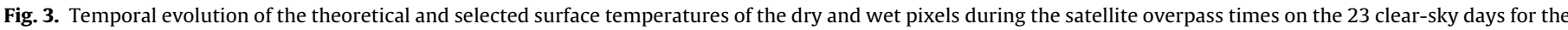
study area (2010130 represents day 130 of year 2010; similarly hereinafter). 
(a)

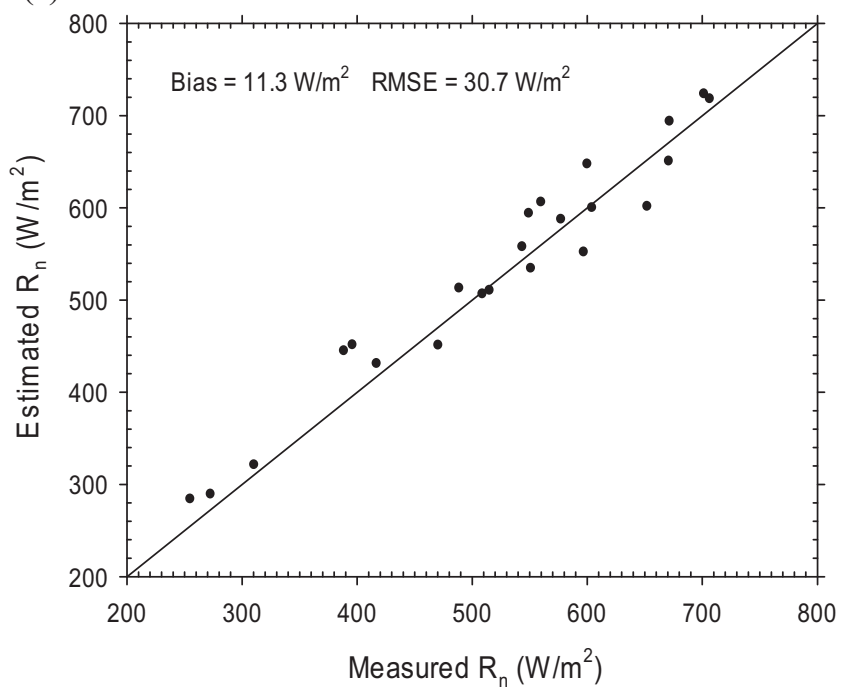

(b)

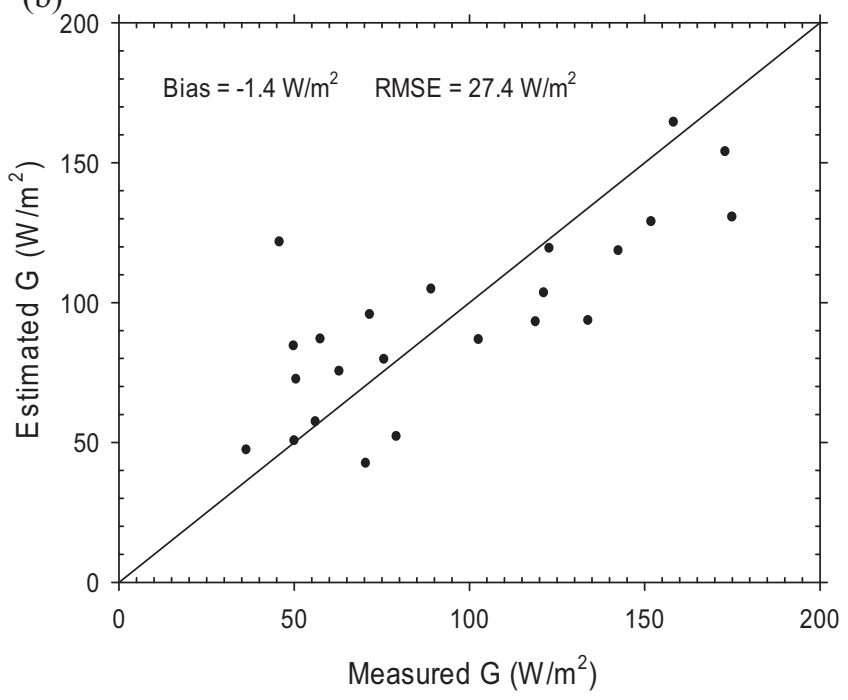

Fig. 4. Comparisons of the estimated instantaneous (a) surface net radiation $\left(R_{n}\right)$ and (b) soil heat flux $(G)$ with the surface measurements at the Yucheng station for the selected MODIS/Terra and MODIS/Aqua overpass times on 23 clear-sky days.

\subsection{Validation of surface energy components}

To make the comparison of the SEBAL model and the $T_{S}-\mathrm{VI}$ triangle model more convincing and theoretically explainable, the surface energy components of the surface net radiation, soil heat flux, sensible heat flux, and latent heat flux derived by the models are first validated against surface measurements to test their reliability. Fig. 4a and b compare the instantaneous surface net radiation $\left(R_{n}\right)$ and soil heat flux $(G)$ estimated using Eqs. (10)-(12) with surface measurements at the Yucheng station from the 23 clear-sky MODIS/Terra and MODIS/Aqua overpass times. Statistical measures of the model performances are presented in Table 3. Both $R_{n}$ and $G$ measurements were reasonably reproduced. When validated with the surface measurement, $R_{n}$ was slightly overestimated by $11.3 \mathrm{~W} / \mathrm{m}^{2}$ (a relative bias of $2.3 \%$ ), with a root mean square error (RMSE) of $30.7 \mathrm{~W} / \mathrm{m}^{2}$ (a relative RMSE of $5.9 \%$ ) and a coefficient of determination $\left(R^{2}\right)$ of 0.951 for the wide range of $R_{n}$. In contrast, $G$ was slightly underestimated, with a bias of $-1.4 \mathrm{~W} / \mathrm{m}^{2}$ (a relative bias of $-1.6 \%$ ), a RMSE of $27.4 \mathrm{~W} / \mathrm{m}^{2}$ (a relative RMSE of $28.7 \%$ ) and a $R^{2}$ of 0.602 . The original equation proposed by Bastiaanssen et al. (1998) in the SEBAL model has seriously
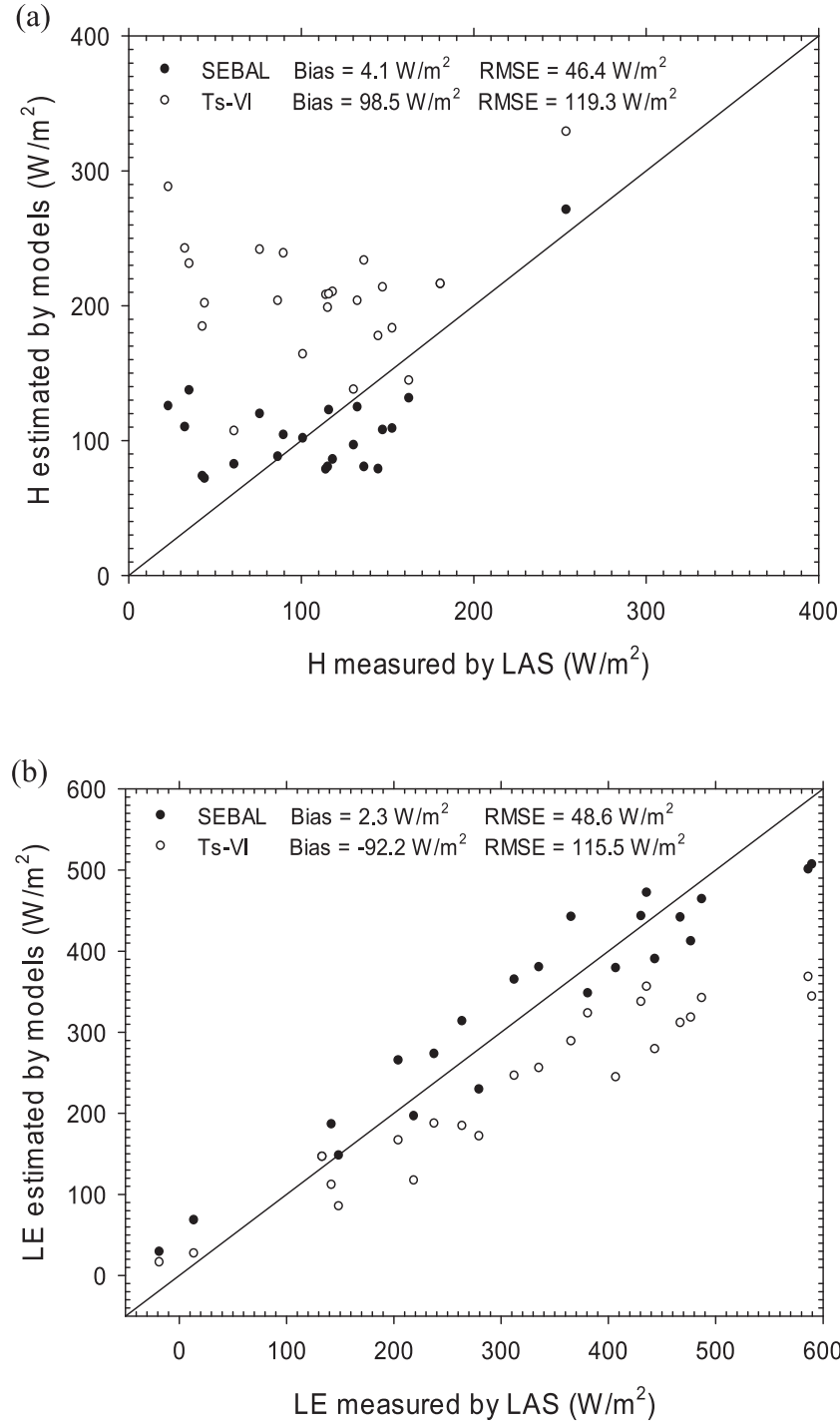

Fig. 5. Comparisons of (a) the sensible heat flux $(H)$ and (b) the latent heat flux (LE) between those estimated by the SEABL model and the $T_{s}$-VI triangle model using selected dry and wet pixels at the Yucheng station and those measured by the LAS at both MODIS/Terra and MODIS/Aqua overpass times. The $H$ estimated by the SEBAL in (a) equals the average of the sensible heat fluxes derived at the two pixels where the transmitter and receiver are located. The LE measured by the LAS equals the average of surface available energy measured at the ground and estimated at the midpoint of the LAS path minus the LAS-measured $H$.

underestimated the surface measurement of $\mathrm{G}$ by $47.4 \mathrm{~W} / \mathrm{m}^{2}$ with a RMSE of $69.4 \mathrm{~W} / \mathrm{m}^{2}$ (not shown here). The results presented here demonstrate the necessity of calibrating the estimate of soil heat flux when the site-specific equation proposed by Bastiaanssen et al. (1998) is applied. Note that the difference in the validation of G estimates is caused partly by the spatial unrepresentativeness of the surface measurement by a single heat flux plate at the scale of a MODIS pixel.

To examine the circumstances in which the $H$ and $E T$ estimates of the SEBAL model are higher/lower than those of the triangle method, the end-members selected manually over the study area (see Fig. 5) and calculated theoretically using the surface energy balance theory (see Fig. 6) are applied to both models for ET comparisons and validations. Studies (Wang et al., 1978; McAneney et al., 1995; Tang et al., 2010) have shown that the area in the middle of the length path of the LAS contributes the most to the measured sensible heat flux, which in this study is located at the boundary of the two pixels in which the transmitter and receiver are 
Table 3

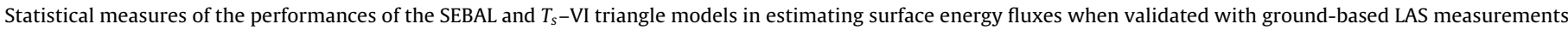

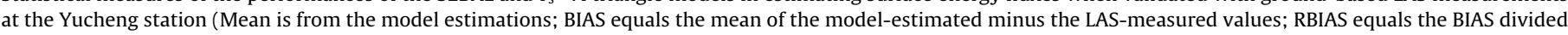
by the LAS-measured mean; RRMSE equals the RMSE divided by the LAS-measured mean; $R^{2}$ is the coefficient of determination).

\begin{tabular}{|c|c|c|c|c|c|c|c|}
\hline & & $\operatorname{Mean}^{\mathrm{a}}\left(\mathrm{W} / \mathrm{m}^{2}\right)$ & $\mathrm{BIAS}\left(\mathrm{W} / \mathrm{m}^{2}\right)$ & RBIAS (\%) & $\operatorname{RMSE}\left(\mathrm{W} / \mathrm{m}^{2}\right)$ & RRMSE (\%) & $R^{2}$ \\
\hline & $R_{n}$ & 533.4 & 11.3 & 2.3 & 30.7 & 5.9 & 0.951 \\
\hline & $G$ & 94.0 & -1.4 & -1.6 & 27.4 & 28.7 & 0.602 \\
\hline \multirow{2}{*}{ SEBAL } & $H$ & 112.8 & 4.1 & 3.9 & 46.4 & 42.7 & 0.337 \\
\hline & LE & 321.6 & 2.3 & 0.8 & 48.6 & 15.2 & 0.926 \\
\hline \multirow{2}{*}{$T_{s}-\mathrm{VI}$} & $H$ & 207.2 & 98.5 & 93.5 & 119.3 & 109.8 & 0.011 \\
\hline & LE & 227.2 & -92.2 & -30.9 & 115.5 & 36.2 & 0.914 \\
\hline
\end{tabular}

a Note that the model-estimated $H$ and LE are the averaged values retrieved from the two pixels where the LAS transmitter and receiver are located whereas the model-

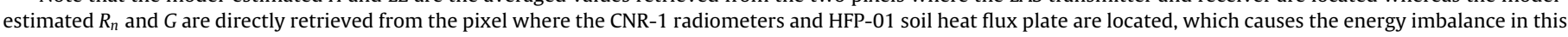
table between the four energy components.

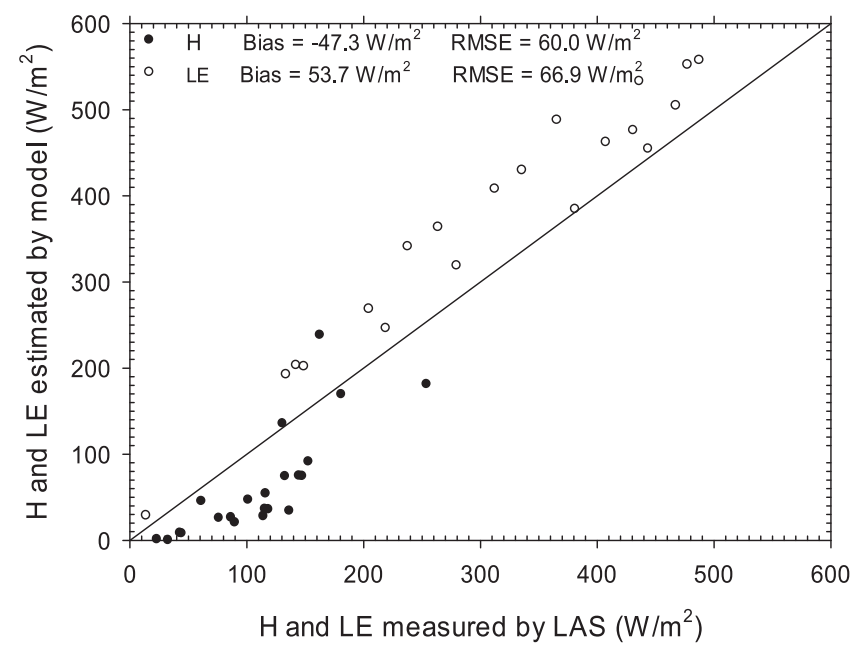

Fig. 6. Comparison of sensible heat flux $(H)$ and latent heat flux (LE) between those estimated by the SEBAL model using the theoretical surface temperature of the dry pixel and the $T_{s}-\mathrm{VI}$-calibrated surface temperature of the wet pixel at the Yucheng station and those measured by the LAS at both MODIS/Terra and MODIS/Aqua overpass times. The $H$ estimated by SEBAL equals the average of the sensible heat fluxes derived at the two pixels where the transmitter and receiver are located. The LE measured by the LAS equals the average of the surface available energy measured at the ground and estimated at the midpoint of the LAS path minus the LAS-measured H.

situated. The two-pixel averaged instantaneous sensible heat flux $(H)$ and latent heat flux (LE) derived by the SEBAL and the $T_{S}-$ VI triangle models using the selected dry and wet pixels over the study area are therefore used for comparisons with the LAS-measured $H$ (Fig. 5a) and LE (Fig. 5b) at the Yucheng station from the 23 clear-sky MODIS/Terra and MODIS/Aqua overpass times. Note that the LAS-measured LE is equal to the average of the surface available energy measured at the ground surface (the pixel where the receiver is located) and estimated at the midpoint (the pixel where the transmitter is located) of the LAS path minus the LAS-measured $H$. Fig. $5 \mathrm{a}$ and b show that the SEBAL model outperformed the $T_{S}-\mathrm{VI}$ triangle model in the $H$ and LE estimation when compared with the LAS measurements. For the SEBAL model, the LAS-measured $H$ and LE were both slightly overestimated with a small positive bias of $4.1 \mathrm{~W} / \mathrm{m}^{2}$ (a relative bias of $3.9 \%$ ) and $2.3 \mathrm{~W} / \mathrm{m}^{2}$ (a relative bias of $0.8 \%$ ), respectively, the RMSEs of $46.4 \mathrm{~W} / \mathrm{m}^{2}$ (a relative RMSE of $42.7 \%$ ) and $48.6 \mathrm{~W} / \mathrm{m}^{2}$ (a relative RMSE of $15.2 \%$ ), respectively, and the $R^{2}$ of 0.337 and 0.926 , respectively. For the $T_{S}$-VI triangle model, the LAS-measured $H$ and LE were significantly overestimated and underestimated, respectively, with large biases of $98.5 \mathrm{~W} / \mathrm{m}^{2}$ (a relative bias of $93.5 \%$ ) and $-92.2 \mathrm{~W} / \mathrm{m}^{2}$ (a relative bias of $-30.9 \%$ ), RMSEs of $119.3 \mathrm{~W} / \mathrm{m}^{2}$ (a relative RMSE of $109.8 \%$ ) and $115.5 \mathrm{~W} / \mathrm{m}^{2}$ (a relative RMSE of $36.2 \%$ ), and $R^{2}$ of 0.011 and 0.914 . When the MODIS overpass corresponds to high or partial fractional cover crop growth stages (LAS-measured $H$ less than $50 \mathrm{~W} / \mathrm{m}^{2}$ or greater than $100 \mathrm{~W} / \mathrm{m}^{2}$, respectively), the SEBAL model had a tendency to overestimate or underestimate LAS-measured $H$, respectively, which may indicate that the surface temperatures of the dry/wet pixels may have been underestimated or overestimated. The $T_{S}-$ VI triangle model was found to overestimate the $H$ and underestimate the LE in most cases, implying that the surface temperatures of the dry or wet pixels were underestimated.

In Fig. 5, it is interesting that all of the SEBAL-derived $H$ values at the Yucheng station are smaller than the $H$ derived by the $T_{S}-\mathrm{VI}$ triangle model, and accordingly, the SEBAL-derived LE values are larger than the LE derived by the $T_{S}-\mathrm{VI}$ triangle model when the same group of dry and wet pixels are used for both models. This pattern signifies that the SEBAL-derived EF from Eq. (3) is larger than the EF derived by the $T_{S}-\mathrm{VI}$ triangle model from Eq. (8). From Eqs. (3), (8), and (9), one can see that the $T_{s}-$ VI triangle method implicitly assumes the multiplication of surface available energy and aerodynamic resistance is invariable (i.e., $F=1$ ) within the study area (in contrast to the SEBAL model), which significantly influences the accuracy of the EF and ET estimates. Moreover, further analysis of Eqs. (3), (8), and (9) indicates that when the multiplication of surface available energy and aerodynamic resistance of a given pixel within the study area is larger (or smaller) than that of the dry pixel (i.e., $F$ is smaller or greater than unity), the EF estimate from the SEBAL model will be larger (or smaller) than that from the $T_{s}-\mathrm{VI}$ triangle model. The comparison result of model-derived $H$ and LE at the Yucheng station is clearly an example of the larger multiplication of surface available energy and aerodynamic resistance than that of the dry pixel.

To test the impact of inappropriate selections of the dry and wet pixels from the study area on the end-member based models, Fig. 6 shows the sensible heat flux and latent heat flux estimated by the SEBAL model using the theoretical surface temperature of the dry pixel and the $T_{S}$-VI triangle model-calibrated surface temperature of the wet pixel (see Section 2.3) at the Yucheng station compared with those measured by LAS at both MODIS/Terra and MODIS/Aqua overpass times. Note that as presented in Section 4.1, the calculation of the theoretical surface temperature of the dry pixel is believed to be reliable at least for the atmospheric and soil conditions at the Yucheng station. However, the calculated theoretical surface temperature of the wet pixel is less convincing primarily because the $T_{S}$-VI triangle model, which does not account for the influence of variations in the surface roughness length, features a very simplified model structure, which may introduce a certain degree of uncertainty in the calculation of the theoretical surface temperature of the wet pixel. The $H$ and LE validation results shown in Fig. 6 have clearly shown that with the use of the theoretical surface temperatures of the dry and wet pixels, the performance of the SEBAL model was worse compared to the performance using the surface temperatures of the selected dry and wet pixels. The 

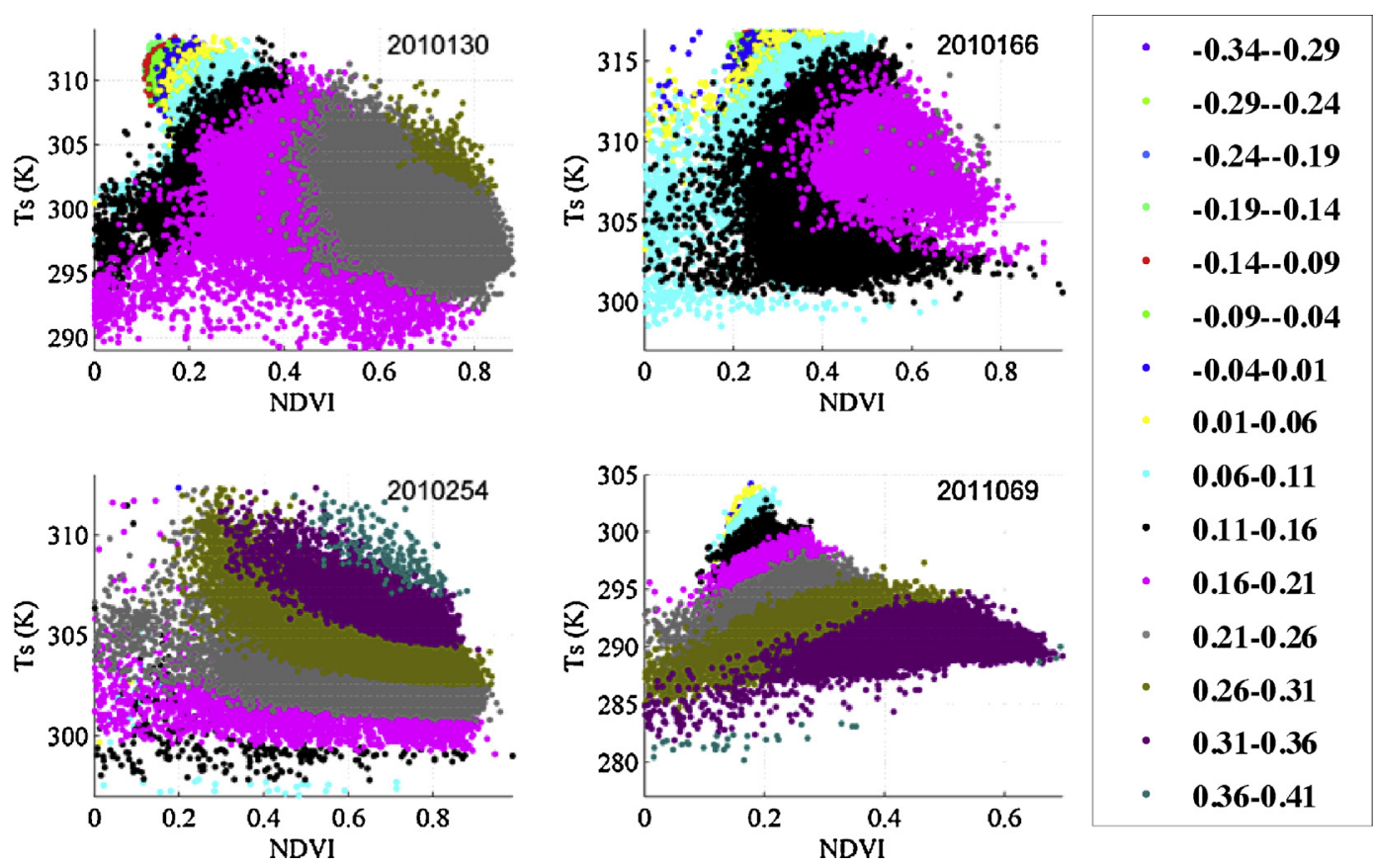

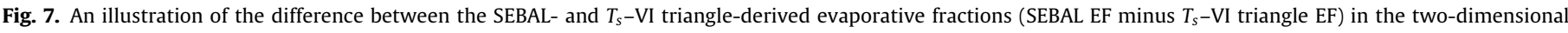

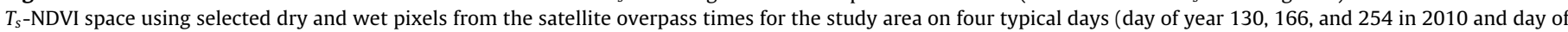
year 69 in 2011), characterized by different crop types, growth stages, and atmospheric conditions.

LAS-measured $H$ and LE values were significantly underestimated and overestimated, respectively, with biases of $-47.3 \mathrm{~W} / \mathrm{m}^{2}$ and $53.7 \mathrm{~W} / \mathrm{m}^{2}$ and a RMSEs of $60.0 \mathrm{~W} / \mathrm{m}^{2}$ and $66.9 \mathrm{~W} / \mathrm{m}^{2}$. The overestimation of LE by the SEBAL model in Fig. 6 indicated that the SEBAL-derived EF was larger than that of the $T_{S}-\mathrm{VI}$ triangle model (1:1 line), which was also found earlier when using the selected dry and wet pixels. The differences in the validations of the SEBALderived $H$ and $L E$ values demonstrate the significance of accurately determining the surface temperatures of the dry and wet pixels.

\subsection{Comparison of spatially distributed $E F$ and $L E$ from both models}

Section 4.2 compared the surface energy components estimated from both the SEBAL model and the $T_{S}-\mathrm{VI}$ triangle model with ground-based LAS measurements at the Yucheng station over 23 clear-sky satellite overpass times. However, that comparison is made essentially at an individual pixel and may not reflect the differences in the model performance for surface conditions that are different from those of the Yucheng station. To more intuitively understand the differences in the model performance, Fig. 7 presents the differences between the SEBAL- and $T_{S}-\mathrm{VI}$ trianglederived evaporative fraction ( $\triangle \mathrm{EF}$ : SEBAL EF minus $T_{S}-\mathrm{VI}$ triangle $\mathrm{EF}$ ) in two-dimensional $T_{S}$-NDVI space using selected dry and wet pixels from the study area during satellite overpass times on four typical days (DOYs 130, 166, and 254 in 2010 and DOY 69 in 2011). These four typical days are characterized by different atmospheric conditions, crop types/growth stages, and surface soil moisture contents. The $\triangle \mathrm{EF}$ was shown to be spatially and temporally variable in the $T_{s}$-NDVI two-dimensional space and in most cases was greater than zero, which meant that the SEBAL-derived EF was larger than the EF derived by the $T_{S}-\mathrm{VI}$ triangle model and that the multiplication of surface available energy and aerodynamic resistance of the dry pixel were smaller than the values of the other intermediate pixels. From Eq. (4), the difference of the aerodynamic resistance between one pixel and another within the study area is clearly shown to be primarily determined by the difference of surface momentum roughness length, which is a function of NDVI and/or vegetation height. Because winter wheat is significantly different from summer corn in plant structure and physiology, the surface momentum roughness length varies greatly even under the same NDVI conditions, which partly explains the different spatial patterns of the $\triangle \mathrm{EF}$ between the four typical days shown in Fig. 7.

$\Delta E F$ can be as large as $\sim 0.4$ on DOY 254 in 2010 during the summer-corn growing season and on DOY 69 in 2011 during the winter wheat growing season but may also be as small as about -0.3 on DOYs 130 and 166 in 2010 during the winter wheat growing season. These values primarily depend on the spatial variations in the surface available energy and the surface momentum roughness length. At the pixels where the magnitudes of NDVI and $T_{S}$ were observed to be similar to those of the dry pixel, the $\Delta E F$ exhibited a negative value (the percentage can be seen from the histograms in Fig. 8), which means that when EF is of a smaller magnitude, the $T_{S}-\mathrm{VI}$-derived EF is likely to be larger than that derived by the SEBAL model. For the pixels that are characterized by medium to high fractional vegetation cover and surface moisture content, the SEBAL-derived EF is obviously larger than the $T_{S}$-VI-derived value. $\triangle E F$ tends to become larger when fractional vegetation cover increases for the pixels that have the same magnitude of $T_{s}$. However, for the same NDVI conditions, no consistent trends were observed for the four typical days. For example, an opposite trend was observed between DOY 254 in 2010 and DOY 69 in 2011.

To quantitatively evaluate the resultant ET differences between the two models in a statistical manner, Fig. 8 illustrates the histograms of the differences of SEBAL- and $T_{S}-\mathrm{VI}$ triangle-derived latent heat flux ( $\triangle \mathrm{LE}$ : SEBAL LE minus $T_{S}-\mathrm{VI}$ triangle $\mathrm{LE}$ ), using selected dry and wet pixels of the study area during the satellite overpass times on the four typical days (DOYs 130, 166, and 254 in 2010 and DOY 69 in 2011). Note that the sign of the $\triangle$ LE is the same as that of $\Delta E F$ because the surface available energy is always a positive value at the daytime satellite overpass. Therefore, the SEBAL-derived LE is shown in most cases to be larger than the $T_{S}-\mathrm{VI}$-derived LE due to the large number of pixels that have a positive $\Delta E F$, as shown in Fig. 7. Depending on the different atmospheric conditions, surface vegetation cover and moisture content 

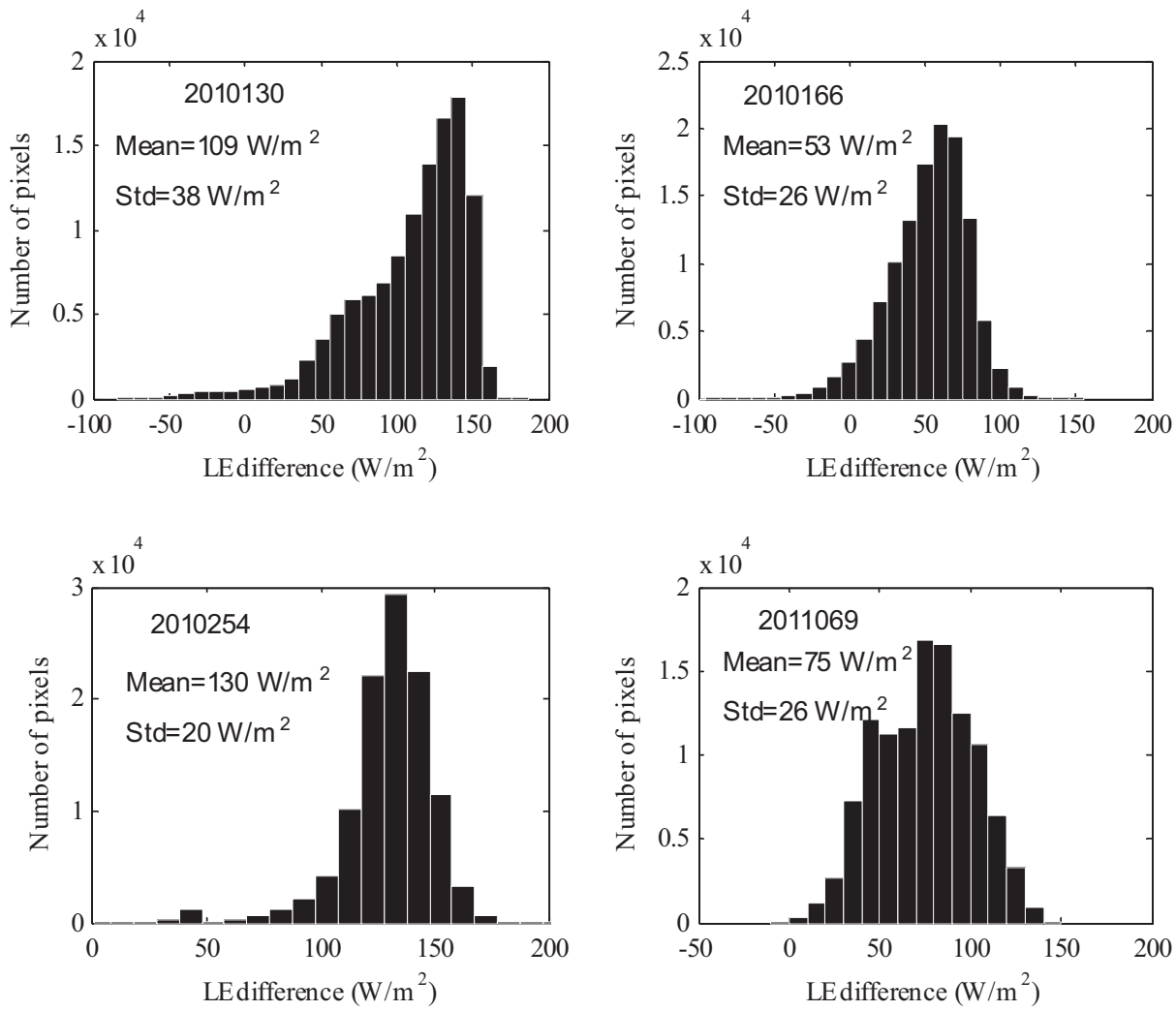

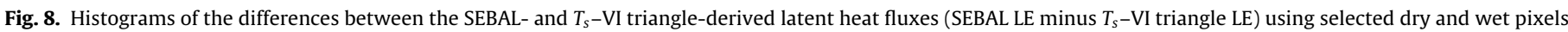

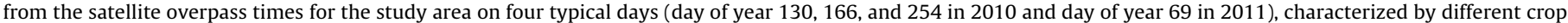
types, growth stages, and atmospheric conditions.

conditions between the four typical days, the areal mean of $\Delta$ LE over the whole study area varies from $53 \pm 26 \mathrm{~W} / \mathrm{m}^{2}$ on DOY 166 in 2010 to $130 \pm 20 \mathrm{~W} / \mathrm{m}^{2}$ on DOY 254 in 2010 . The $\Delta$ LE values were shown to be in a general range from $-50 \mathrm{~W} / \mathrm{m}^{2}$ near the dry pixel to $160 \mathrm{~W} / \mathrm{m}^{2}$ near the wet pixel. The upper and lower limits of $\Delta \mathrm{LE}$ change between the different days and are partly determined by the differences in the surface momentum roughness between the dry pixel and the (partially and fully) vegetated area. The difference of the surface momentum roughness length between winter wheat and summer corn has resulted in a significantly different spatial distribution of $\Delta$ LE, e.g., between DOY 130 and 254 in 2010. When the LE dominates the partitioning of the surface available energy, the majority of pixels will have a $\Delta \mathrm{LE}$ of $>50 \mathrm{~W} / \mathrm{m}^{2}$.

\subsection{Discussion of factors controlling the difference between the two models}

The SEBAL model was developed to reduce the input of near-surface air temperature as required by the commonly used one-source surface energy bulk transfer equation. The $T_{S}-\mathrm{VI}$ triangle model, which does not account for the variation in the surface available energy and aerodynamic resistance across different fractional vegetation coverage, soil moisture conditions, or vegetation types but does have the same definition of dry and wet pixels, can be overall regarded as a further simplification of the SEBAL model (see Eqs. (3), (8), and (9)).

In the following, we discuss in detail how the EF and the ET in both models are influenced by their respective controlling factors. For the SEBAL model, assuming the variation of $\left(R_{n}-G\right)_{d r y}$ is less dependent on $T_{s, \text { dry }}$ and the estimation of $R_{n}-G$ for a given pixel is highly accurate, the uncertainty of the EF estimate is determined only by the variations in $T_{s, d r y}, T_{s, w e t}$, and $R_{a}$. The total derivative of EF as a function of $T_{s, d r y}, T_{s, w e t}$, and $z_{o m}$ in the SEBAL model and as a function of $T_{s, \text { dry }}$ and $T_{s, \text { wet }}$ in the $T_{S}-$ VI triangle model can be expressed as follows.

For the SEBAL model,

$$
\begin{aligned}
\partial \mathrm{EF} & =\frac{\partial \mathrm{EF}}{\partial T_{s, d r y}} \delta T_{s, d r y}+\frac{\partial \mathrm{EF}}{\partial T_{s, \text { wet }}} \delta T_{s, \text { wet }}+\frac{\partial \mathrm{EF}}{\partial R_{a}} \delta R_{a} \\
& \approx \frac{\left(R_{n}-G\right)_{d r y} R_{a, d r y}}{\left(R_{n}-G\right) R_{a}} \frac{T_{s}-T_{s, \text { wet }}}{\left(T_{s, d r y}-T_{s, \text { wet }}\right)^{2}} \delta T_{s, d r y}+\frac{\left(R_{n}-G\right)_{d r y} R_{a, d r y}}{\left(R_{n}-G\right) R_{a}} \frac{T_{s, d r y}-T_{s}}{\left(T_{s, d r y}-T_{s, \text { wet }}\right)^{2}} \delta T_{s, \text { wet }}+\frac{\left(R_{n}-G\right)_{d r y} R_{a, d r y}}{\left(R_{n}-G\right)\left(R_{a}\right)^{2}} \frac{T_{s}-T_{s, \text { wet }}}{T_{s, d r y}-T_{s, \text { wet }}} \delta R_{a} \\
& =F \times \frac{T_{s}-T_{s, \text { wet }}}{\left(T_{s, \text { dry }}-T_{s, \text { wet }}\right)^{2}} \delta T_{s, d r y}+F \times \frac{T_{s, d r y}-T_{s}}{\left(T_{s, d r y}-T_{s, \text { wet }}\right)^{2}} \delta T_{s, \text { wet }}+F \times \frac{1}{R_{a}} \frac{T_{s}-T_{s, \text { wet }}}{T_{s, \text { dry }}-T_{s, \text { wet }}} \delta R_{a}
\end{aligned}
$$

For the $T_{S}-$ VI triangle model,

$$
\partial \mathrm{EF}=\frac{\partial \mathrm{EF}}{\partial T_{s, d r y}} \delta T_{s, d r y}+\frac{\partial \mathrm{EF}}{\partial T_{s, \text { wet }}} \delta T_{s, \text { wet }}=\frac{T_{s}-T_{s, \text { wet }}}{\left(T_{s, \text { dry }}-T_{s, \text { wet }}\right)^{2}} \delta T_{s, \text { dry }}+\frac{T_{s, d r y}-T_{s}}{\left(T_{s, \text { dry }}-T_{s, \text { wet }}\right)^{2}} \delta T_{s, \text { wet }}
$$


Because the dry pixel is generally characterized by a higher surface albedo, a higher surface temperature, and a higher fraction of soil heat flux to surface net radiation, the surface available energy $\left(R_{n}-G\right)_{d r y}$ of this pixel will be smaller than that for the other intermediate pixels under a given atmospheric condition. In some cases, this $R_{n}-G$ difference can be of a similar magnitude as $\left(R_{n}-G\right)_{d r y}$. The $R_{a, d r y} / R_{a}$ in Eq. (15) can be simply approximated to be $\ln \left(200 / z_{\text {om,dry }}\right) / \ln \left(200 / z_{\text {om }}\right)$ if neutral atmospheric conditions are assumed (see Eq. (4)). When $z_{o m}$ ( 0.125 times vegetation height) increases from a minimum of $0.005 \mathrm{~m}$ to a maximum of $0.1 \mathrm{~m}$ for the winter wheat ( $0.3 \mathrm{~m}$ for the summer corn), $R_{a, d r y} / R_{a}$ will increase accordingly between 1.0 and $\sim 1.4$ ( $\sim 1.6$ for summer corn), under the condition of $z_{o m, d r y}=0.005 \mathrm{~m}$. The smaller $R_{n}-G$ but larger $\ln \left(200 / z_{o m}\right)$ of the dry pixel relative to other pixels causes the $\mathrm{F}$ factor in Eq. (15) to be smaller than unity in most cases, as shown in Section 4.3, which further contributed to the SEBAL-derived EF being less sensitive to $T_{s, d r y}$ and $T_{s, \text { wet }}$ than the $T_{s}$-VI-derived EF. When the F factor in Eq. (3) is greater or smaller than (or equal to) unity, the SEBAL model will produce a lower or higher (or equal to) EF than the $T_{S}-$ VI triangle model.

Previous studies (Timmermans et al., 2007; Tang et al., 2010, 2013; Long et al., 2011) have clearly shown the importance of reasonably determining the surface temperatures of the dry and wet pixels for the two end-member-based models. For example, a systematic overestimation or underestimation in the SEBAL modelderived $H$ and LE values is found when the surface temperatures of the dry and wet pixels are varied for a given study area (Long et al., 2011). By varying the selected end-members over the given study area, Long and Singh (2013) further found that increasing/decreasing the temperature at the dry (or wet) pixel could lead to an increase/a decrease in the EF and ET estimates in the SEBAL model. For a detailed understanding of how the variation of dry and wet pixels quantitatively affects the regional $H$ and LE estimates in the SEBAL model, readers are strongly recommended to refer to the work of Tang et al. (2013), in which the analytical equations are proposed. For the $T_{s}-\mathrm{VI}$ triangle method, Tang et al. (2011b) found that the underestimation of the surface temperature at the dry pixel can cause the underestimation of EF and demonstrated the difficulty to identify the limiting dry edge in subhumid regions within a satellite scene. These previous findings are consistent with our analytical derivations as shown in Eqs. (15) and (16) and of great significance in calibrating the SEBAL and $T_{s}-\mathrm{VI}$ triangle model when it is necessary. Because the end-members vary with the spatial domain, pixel size, and quality of the satellite images (Long et al., 2012; Long and Singh, 2013), they cannot be appropriately selected in general. To reduce the requirement of both dry and wet pixels in a scene, Norman et al. (2006) suggested improving the SEBAL-estimated $H$ and LE by combining the two-source land surface formulation for a calibration. The estimation of surface momentum roughness length, which determines the magnitude of the variations of $H$ and LE in the SEBAL model, is likely to be of great uncertainty across different fractional vegetation coverage and plant functional types. Although the surface momentum roughness length is shown to not be a sensitive parameter in the estimation of $H$ and LE (Long et al., 2011), it does affect the estimation of aerodynamic resistance, especially when several vegetation types characterized by markedly different surface roughness lengths are present within the study area. Timmermans et al. (2007) found that errors in roughness determination at the dry pixel may corrupt flux estimates over areas that have moisture and roughness significantly different from those at the dry pixel. These two factors partly make the SEBAL-derived $H$ and LE values different from the $T_{S}-\mathrm{VI}$ triangle-derived values.

For the $T_{s}$-VI triangle model, no parameters other than the surface temperatures of the dry and wet pixels impact the regional estimates of ET for a given pixel. Once the dry and wet pixels are selected in the $T_{S}$-VI triangle, the pixels with the same surface temperature but the different fractional vegetation coverage, surface soil moisture content, and/or vegetation type will have the same ET estimate, which seems theoretically unreasonable. In other words, the $T_{s}$-VI triangle model may be only useful for regional EF estimates when significant differences in roughness length within the study area do not exist. The lack of consideration of the variations in the surface available energy and aerodynamic resistance in the $T_{S}-\mathrm{VI}$ triangle model has increased the sensitivity of the modelderived EF to the surface temperature of the dry and wet pixels but accordingly decreased the model performance. For example, if the air temperature at the Yucheng station or the surface temperature over a water body surface is used as the theoretical surface temperature of the wet pixel instead of the $T_{S}$-VI-calibrated surface temperature in Fig. 6, the RMSE for the validation of the SEBAL-derived $H$ and LE would be decreased to approximately $70-80 \mathrm{Wm}^{2}$, but the RMSE of the $T_{S}-\mathrm{VI}$ triangle model is approximately $80-120 \mathrm{~W} / \mathrm{m}^{2}$.

The SEBAL model produces larger EF and ET than the $T_{S}-\mathrm{VI}$ triangle model for most pixels over a given study area when the same group of dry and wet pixels is applied, especially for pixels characterized by medium to high vegetation fractions or surface soil moisture contents. This finding is corroborated by the work of Long and Singh (2013) who have found that the bias/mean for the triangle method was smaller than for the SEBAL model when the LE estimated from the two models was validated/compared. Exceptions may happen for the pixels that have similar magnitudes of NDVI and $T_{s}$ to the dry pixel. The high sensitivity of the parameterized $\mathrm{EF}$ to the surface temperatures of the dry and wet pixels makes the $T_{S}-\mathrm{VI}$ triangle model difficult to accurately estimate regional $\mathrm{EF}$ and ET. The oversimplification of the EF parameterization causes the large biases in the $T_{S}-\mathrm{VI}$ triangle model-estimated $H$ and LE when validated against the LAS measurements. To reduce its sensitivity to the surface temperature of the dry and wet pixels and improve the EF estimates between different vegetation types, the $T_{s}-\mathrm{VI}$ triangle model may be required to incorporate the variations in surface momentum roughness length and surface available energy.

Besides the difference in the model structure, the uncertainty of the model inputs (including MODIS data and other meteorological variables) is another source of error in the distinct EF and ET estimates from the two models. However, because the effect of the uncertainties of the model inputs on the model-derived sensible heat flux and latent heat flux has been partly or detailedly discussed for both the SEBAL and $T_{s}-\mathrm{VI}$ triangle models in previous papers by several authors (Timmermans et al., 2007; Tang et al., 2010, 2013; Long et al., 2011), we have primarily focused on the causes and effects of the differences between the two models' estimated sensible heat fluxes and latent heat fluxes and what controls the heat flux differences through analytical deduction and model applications in this study. Our sensitivity analysis (not shown in this study) shows that an increase of $1 \mathrm{~K}$ in the MODIS temperature for the given pixel averagely results in a decrease of $17.6 \pm 7.7$ $(19.5 \pm 11.2) \mathrm{W} / \mathrm{m}^{2}$ in the SEBAL $\left(T_{S}-\mathrm{VI}\right.$ triangle)-estimated $H$ at the Yucheng station whereas a systematic variation of $1 \mathrm{~K}$ in the MODIS temperature over the whole study area contributes to negligible variations of $H$ and LE. The relative variation of the SEBAL-estimated $H$ is of similar magnitude to the finding by Long et al. (2011).

Similar to most validation studies in the literature, this work does not contain multi-site $H$ and LE measurements conducted simultaneously over several vegetation types characterized by significantly different surface roughness lengths and physiological characteristics. When the multi-site $H$ and LE measurements are used for ground-based validation, the superiority of the SEBAL model to the $T_{S}$-VI triangle model may be more apparent because the effect of surface roughness length between different vegetation 
types has been clearly accounted for in the SEBAL model. Moreover, when the size of the study area is large, the surface available energy may change greatly in space, and neglecting its variation (by assuming it to be spatially invariable) in the $T_{s}-\mathrm{VI}$ triangle may cause a bias in the EF and ET estimates.

\section{Summary and conclusion}

This study comprehensively evaluates two typical endmember-based models that have been widely applied worldwide. The results help to fully and explicitly understand the differences of the SEBAL- and $T_{S}$-VI-derived EF and ET values, which have not been well addressed in previous studies. Through an analytical deduction as shown in Eq. (3), the differences between SEBALand $T_{S}-\mathrm{VI}$-derived regional $\mathrm{EF}$ and $\mathrm{ET}$ and the factors that govern these differences are clearly shown. To quantify the difference of the model performance in practical applications, both models are assessed using selected dry and wet pixels based on MODIS data from 23 clear-sky overpass times between January 2010 and late October 2011 for a study area on the North China plain. Because several authors have previously presented the sensitivity analysis of the SEBAL and $T_{S}-$ VI triangle models, we have primarily focused on discussing the causes and effects of their differences in this study. The conclusions can be primarily summarized as follows:

(1) The $H$ and LE estimates in the $T_{S}$-VI triangle model are generally more sensitive to surface temperatures of the dry and wet pixels than those in the SEBAL model because the smaller $R_{n}-G$ but larger $\ln \left(200 / z_{\text {om }}\right)$ of the dry pixel relative to other pixels causes the $F\left(=\left[\left(R_{n}-G\right)_{d r y} \times R_{a, d r y}\right] /\left[\left(R_{n}-G\right) \times R_{a}\right]\right)$ factor to be smaller than unity in most cases, which has been demonstrated by both the analytical analysis and model applications.

(2) When the F factor in Eq. (3) is greater or smaller than (or equal to) unity, the SEBAL model will produce a lower or higher (or equal) $\mathrm{EF}$ than the $T_{S}$-VI triangle model.

(3) The SEBAL-derived EF and ET for most pixels is greater than those derived by the $T_{S}-\mathrm{VI}$ triangle model when the same group of dry and wet pixels is applied, especially for pixels characterized by medium to high vegetation fractions or surface soil moisture contents. Exceptions may occur when the pixels have magnitudes of NDVI and $T_{s}$ that are similar to the dry pixel. The EF difference (SEBAL minus $T_{S}-\mathrm{VI}$ triangle) between the two models is highly variable on different days and can be as low as approximately -0.34 and as high as $\sim 0.4$.

(4) The oversimplification of the EF parameterization in the $T_{S}-\mathrm{VI}$ triangle model is responsible for the large biases in the $H$ and LE validations versus the LAS measurements. To reduce its sensitivity to the surface temperature of the dry and wet pixels and to differentiate the EF estimates between different vegetation types with the same surface temperature, the $T_{s}$-VI triangle model may be further improved by incorporating the effect of the variations in surface momentum roughness length in the future.

(5) Neglecting the spatial variation in the surface available energy is somewhat problematic and also partly results in the biases in the EF estimates in the $T_{S}-\mathrm{VI}$ triangle model. The surface available energy over the study area has been shown to vary greatly with the areal mean (excluding the mountainous area, not shown) on most days averaging 1.3-1.6 times the value of the selected dry pixel.

(6) The high sensitivity of the parameterized EF to surface temperatures of the dry and wet pixels makes the $T_{S}$-VI triangle model difficult to accurately estimate regional EF and ET.

(7) The SEBAL model is able to produce satisfactory $H$ and LE values at the MODIS pixel scale when compared to ground-based LAS measurements, with small biases of $4.1 \mathrm{~W} / \mathrm{m}^{2}$ and $2.3 \mathrm{~W} / \mathrm{m}^{2}$ and RMSEs of $46.4 \mathrm{~W} / \mathrm{m}^{2}$ and $48.6 \mathrm{~W} / \mathrm{m}^{2}$, respectively. However, the $T_{s}-$ VI triangle model produces much worse $H$ and LE estimates, with biases of $98.5 \mathrm{~W} / \mathrm{m}^{2}$ and $-92.2 \mathrm{~W} / \mathrm{m}^{2}$ and RMSEs of $119.3 \mathrm{~W} / \mathrm{m}^{2}$ and $115.5 \mathrm{~W} / \mathrm{m}^{2}$, respectively.

The validation results at the Yucheng station in this study are primarily associated with unstressed vegetation. Under the waterstressed conditions of the deep root zone (e.g., in the arid and semi-arid areas), several authors (Norman et al., 2006; Gokmen et al., 2012; Wang and Dickinson, 2012) have suggested incorporating the level of water stress into the model parameterization to improve the estimation of sensible heat flux and latent heat flux in the one-source energy balance models. Both the SEBAL model and the $T_{S}$-VI triangle model may be of limited use when deep-layer soil moisture is moderately to significantly stressed. Future studies are strongly recommended to test the capability of both models under the water-stressed conditions. Another possible improvement for the SEBAL model is to use a spatially variable heat roughness length rather than fixing it to a constant value of $0.1 \mathrm{~m}$ (see Eq. (4)), which is in agreement with suggestions recently made by Paul et al. (2014).

\section{Acknowledgments}

We acknowledge the hard-working staff members at the Yucheng Comprehensive Experimental Station, who cooperatively provided the ground- and near-surface measurements used in this study. This work was partly supported by the National Natural Science Foundation of China under Grant 41201366, the Institute of Geographic Sciences and Natural Resources Research funded outstanding young talent project under Grant 2013RC201, and the National Natural Science Foundation of China under Grant 41101332.

\section{References}

Bastiaanssen, W.G.M., Menenti, M., Feddes, R.A., Holtslag, A.A.M., 1998. A remote sensing surface energy balance algorithm for land (SEBAL). 1. Formulation. J. Hydrol. 212, 198-212.

Bastiaanssen, W.G.M., Noordman, E.J.M., Pelgrum, H., Davids, G., Thoreson, B.P. Allen, R.G., 2005. SEBAL model with remotely sensed data to improve waterresources management under actual field conditions. J. Irrig. Drain. Eng. 131 (1), 85-93.

Bastiaanssen, W.G.M., (Ph.D. thesis) 1995. Regionalization of surface flux densities and moisture indicators in composite terrain. Wageningen Agricultural University, Wageningen, The Netherlands.

Carlson, T., 2007. An overview of the triangle method for estimating surface evapotranspiration and soil moisture from satellite imagery. Sensors 7 (8), 1612-1629.

Carlson, T.N., Gillies, R.R., Schmugge, T.J., 1995. An interpretation of methodologies for indirect measurement of soil water content. Agric. For. Meteorol. 77, 191-205.

Gokmen, M., Vekerdy, Z., Verhoef, A., Verhoef, W., Batelaan, O., Van Der Tol, C., 2012. Integration of soil moisture in SEBS for improving evapotranspiration estimation under water stress conditions. Remote Sens. Environ. 121, 261-274.

Jiang, L., Islam, S., 1999. A methodology for estimation of surface evapotranspiration over large areas using remote sensing observations. Geophys. Res. Lett. 26 (17), 2773-2776.

Jiang, L., Islam, S., 2001. Estimation of surface evaporation map over southern Great Plains using remote sensing data. Water Resour. Res. 37 (2), 329-340.

Jiang, L., Islam, S., Carlson, T.N., 2004. Uncertainties in latent heat flux measurement and estimation: implications for using a simplified approach with remote sensing data. Can. J. Rem. Sens. 30, 769-787.

Kalma, J.D., McVicar, T.R., McCabe, M.F., 2008. Estimating land surface evaporation: a review of methods using remotely sensed surface temperature data. Surv. Geophys. 29 (4-5), 421-469.

Lambin, E.F., Ehrlich, D., 1996. The surface temperature-vegetation index space for land cover and land-cover change analysis. Int. J. Remote Sens. 17, 463-487.

Li, Z.-L., Stoll, M.P., Zhang, R.H., Jia, L., Su, Z., 2001. On the separate retrieval of soil and vegetation temperatures from ATSR data. Ser. D Earth Sci. 44 (2), 97-111.

Li, Z.-L., Zhang, R.H., Sun, X.M., Su, H.B., Tang, X.Z., Zhu, Z.L., Sobrino, J.A., 2004 Experimental system for the study of the directional thermal emission of natural surfaces. Int. J. Remote Sens. 25 (1), 195-204.

Li, Z.-L., Tang, R., Wan, Z., Bi, Y., Zhou, C., Tang, B., Yan, G., Zhang, X., 2009. A review of current methodologies for regional evapotranspiration estimation from remotely sensed data. Sensors 9 (5), 3801-3853. 
Li, Z.-L., Tang, B.H., Wu, H., Ren, H., Yan, G., Wan, Z., Trigo, I., Sobrino, J.A., 2013a. Satellite-derived land surface temperature: current status and perspectives. Rem. Sens. Environ. 131, 14-37.

Li, Z.-L., Wu, H., Wang, N., Qiu, S., Sobrino, J.A., Wan, Z., Tang, B., Yan, G., 2013b. Land surface emissivity retrieval from satellite data. Int. J. Remote Sens. 34 (9-10), 3084-3127.

Liang, S.L., 2004. Quantitative Remote Sensing of Land Surfaces. John Wiley \& Sons, New Jersey.

Long, D., Singh, V.P., Li, Z.-L., 2011. How sensitive is SEBAL to changes in input variables, domain size and satellite sensor? J. Geophys. Res. 116, D21107.

Long, D., Singh, V.P., Scanlon, B.R., 2012. Deriving theoretical boundaries to address scale dependencies of triangle models for evapotranspiration estimation. J. Geophys. Res. 117 (D5), D05113.

Long, D., Singh, V.P., 2013. Assessing the impact of end-member selection on the accuracy of satellite-based spatial variability models for actual evapotranspiration estimation. Water Resour. Res. 49 (5), 2601-2618.

McAneney, K.J., Green, A.E., Astill, M.S., 1995. Large-aperture scintillometry: the homogeneous case. Agric. For. Meteorol. 76, 149-162.

Merlin, O., Chirouze, J., Olioso, A., Jarlan, L., Chehbouni, G., Boulet, G., 2014. An image-based four-source surface energy balance model to estimate crop evapotranspiration from solar reflectance/thermal emission data (SEB-4S). Agric. For. Meteorol. 184, 188-203.

Moran, M.S., Clarke, T.R., Inoue, Y., Vidal, A., 1994. Estimating crop water deficit using the relation between surface-air temperature and spectral vegetation index. Remote Sens. Environ. 49 (3), 246-263.

Nemani, R.R., Running, S.W., 1989. Estimation of regional surface resistance to evapotranspiration from NDVI and thermal-IR AVHRR data. J. Appl. Meteorol. 28, 276-284

Nishida, K., Nemani, R.R., Running, S.W., Glassy, J.M., 2003. An operational remote sensing algorithm of land surface evaporation. J. Geophys. Res. 108 (D9), 4270.

Norman, J.M., Anderson, M.C., Kustas, W.P.,2006, August. Are single-source, remotesensing surface-flux models too simple? In: Earth Observation for Vegetation Monitoring and Water Management, vol. 852, No. 1. AIP Publishing, pp. 170-177.

Paul, G., Gowda, P.H., Vara Prasad, P.V., Howell, T.A., Aiken, R.M., Neale, C.M., 2014 Investigating the influence of roughness length for heat transport $\left(\mathrm{z}_{\mathrm{oh}}\right)$ on the performance of SEBAL in semi-arid irrigated and dryland agricultural systems. J. Hydrol. 509, 231-244.

Paulson, C.A., 1970. The mathematical representation of wind speed and temperature profiles in the unstable atmospheric surface layer. J. Appl. Meteorol. 9 (6), 857-861.
Priestley, C.H.B., Taylor, R.J., 1972. On the assessment of surface heat flux and evaporation using large-scale parameters. Mon. Weather Rev. 100 (2), 81-92.

Prihodko, L., Goward, S.N., 1997. Estimation of air temperature from remotely sensed surface observations. Remote Sens. Environ. 60, 335-346.

Roerink, G.J., Su, Z., Menenti, M., 2000. S-SEBI: a simple remote sensing algorithm to estimate the surface energy balance. Phys. Chem. Earth Part B. 25 (2), 147-157.

Stisen, S., Sandholt, I., Nørgaard, A., Fensholt, R., Jensen, K.H., 2008. Combining the triangle method with thermal inertia to estimate regiona evapotranspiration-applied to MSG/SEVIRI data in the Senegal River basin. Remote Sens. Environ. 112, 1242-1255.

Su, Z., 2002. The Surface Energy Balance System (SEBS) for estimation of turbulent heat fluxes. Hydrol. Earth Syst. Sci. 6 (1), 85-100.

Tang, R., Li, Z.-L., Tang, B.H., 2010. An application of the $T_{s}-$ VI triangle method with enhanced edges determination for evapotranspiration estimation from MODIS data in arid and semi-arid regions: implementation and validation. Remote Sens. Environ. 114, 540-551.

Tang, R., Li, Z.-L., Chen, K.S., 2011a. Validating MODIS-derived land surface evapotranspiration with in situ measurements at two AmeriFlux sites in a semiarid region. J. Geophys. Res. 116 (D4), D04106.

Tang, R., Li, Z.-L., Jia, Y., Li, C., Sun, X., Kustas, W.P., Anderson, M.C., 2011b. An intercomparison of three remote sensing-based energy balance models using Large Aperture Scintillometer measurements over a wheat-corn production region. Rem. Sens. Environ. 115 (12), 3187-3202.

Tang, R., Li, Z.-L., Chen, K.S., Jia, Y., Li, C., Sun, X., 2013. Spatial-scale effect on the SEBAL model for evapotranspiration estimation using remote sensing data. Agric. For. Meteorol. 174, 28-42.

Timmermans, W.J., Kustas, W.P., Anderson, M.C., French, A.N., 2007. An intercomparison of the surface energy balance algorithm for land (SEBAL) and the two-source energy balance (TSEB) modeling schemes. Remote Sens. Environ. 108 (4), 369-384

Venturini, V., Bisht, G., Islam, S., Jiang, L., 2004. Comparison of evaporative fractions estimated from AVHRR and MODIS sensors over South Florida. Remote Sens. Environ. 93, 77-86.

Wang, K., Dickinson, R.E., 2012. A review of global terrestrial evapotranspiration: observation, modeling, climatology, and climatic variability. Rev. Geophys. 50 (2), RG2005.

Wang, T.I., Ochs, G.R., Clifford, S.F., 1978. A saturation-resistant optical scintillomete to measure $\mathrm{Cn}^{2}$. J. Opt. Soc. Am. 68, 334-338.

Zhang, R.H., Sun, X., Wang, W., Xu, J., Zhu, Z., Tian, J., 2005. An operational twolayer remote sensing model to estimate surface flux in regional scale: physical background. Ser. D Earth Sci. 48, 225-244 